\title{
Measuring Tail Risks at High Frequency
}

\author{
Brian Weller* \\ Duke University
}

November 1, 2016

\begin{abstract}
I use the cross section of bid-ask spreads to develop a new measure of extreme event risk. Simple regressions relating spreads and trading volume to factor betas deliver high-frequency tail risk estimates for common factors in stock returns. Equilibrium spreads embed tail risk information because sharp changes in asset values harm liquidity providers, and the cross section of spreads reveals factor risks because greater factor exposures increase potential costs. My methodology disentangles financial and aggregate market risks during the 2007-2008 Financial Crisis; quantifies jump risks associated with FOMC announcements; and anticipates extreme market risks before the 2010 Flash Crash.

JEL: C58, G01, G12, G14, G17

Keywords: Tail Risks, High-Frequency Market Making, Bid-Ask Spreads
\end{abstract}

\footnotetext{
*brian.weller@duke.edu. Tel: +1 919660 1720. Website: https://sites.google.com/site/brianmweller/. Thanks for many helpful comments to the Editor and two referees, Torben Andersen, Snehal Banerjee, Eric Budish, Anna Cieslak, Nicolas Crouzet, Ian Dew-Becker, Thierry Foucault, Ravi Jagannathan, Bryan Kelly, Robert Korajczyk, Xu Lu, Konstantin Milbradt, Marina Niessner, Dimitris Papanikolaou, John Shim, and Viktor Todorov, Haoxiang Zhu, my discussants Mikhail Chernov, Dobrislav Dobrev, Arie Gozluklu, Eric Jondeau, Thomas Katzschner, and Allan Timmermann, and seminar participants at Northwestern Kellogg, HEC Paris, University of Lausanne and EPFL, Duke University, the NBER Asset Pricing Meeting, the 4th Industrial Organisation of Securities and Derivatives Markets Conference, the 11th Annual Central Bank Conference on the Microstructure of Financial Markets, the 12th Annual Meeting of the Financial Research Association, and the Paris December International Finance Meeting for valuable comments and discussion.
} 


\section{Introduction}

Fear of extreme market movements lies at the heart of rare disasters explanations for the equity premium. Although crashes are readily identified after the fact, anticipating extreme events remains a pressing challenge. The rarity of extreme market events complicates the assessment of disaster risks using standard dynamic forecasting techniques on historical data. For this reason, existing approaches to risk assessment instead typically use options data to extract market forecasts of extreme events. However, the availability of liquid, deep out-of-the-money options limits these procedures' estimation frequency and potential scope. The objective of this paper is to introduce a complementary methodology to overcome these limitations.

In this paper, I exploit the cross section of bid-ask spreads to develop a new, real-time measure of extreme event risk. By drawing on high-frequency quote data for thousands of U.S. stocks, I advance conditioning frequencies from months to minutes and the set of potential factors from those with

liquid traded options to any factors that explain the cross section of realized stock returns. More generally, I demonstrate that information recovered from the behavior of market intermediaries offers a rich new resource for understanding aggregate economic shocks and potential systemic threats. Rather than impeding the recovery of information about factor risks, trading frictions themselves embed a wealth of unexploited information about future price movements.

Extreme market events take many forms, and the tail risks detected by my approach consist primarily of sharp and sudden factor crashes or jumps. This set of anticipated risks encompasses sharp factor price movements of several basis points, on the order of the median half-spread, to extreme price jumps, realized, for example, during the Black Monday crash of October 19, 1987, or during any of several market crashes at the height of the 2007-2008 Financial Crisis. These extreme market movements jeopardize years of investment returns in minutes or hours, and they are endemic to equity, currency, and commodity markets alike. Such tail realizations are particularly damaging to market makers because they are difficult to hedge and translate into trading losses with high probability, but they are also of broader concern to market participants and policymakers because they occur too quickly to be managed well.

The market-making sector provides a natural setting for recovering conditional estimates of 
anticipated risks. ${ }^{1}$ Liquidity providers set quotes to balance expected gains from intermediation against potential losses from trading against better-informed market participants. One important source of adverse selection derives from failing to adjust quotes in response to sudden changes in the latent value of an asset before another party trades against them. Large factor innovations are especially damaging to market makers because such "picking-off" losses may be realized in many securities simultaneously. High-frequency liquidity providers harness extensive market data and advanced algorithms to manage this source of risk, and they continually revise their quotes in response to anticipated sudden price changes. Prevailing quotes thus reflect market-maker risk assessments on a near-instantaneous basis for every exchange-traded security. ${ }^{2}$

My approach extracts tail risk estimates using this quote information for a large cross section of stocks. The technique consists of a simple empirical system in the style of Fama and MacBeth (1973) regressions for estimating factor prices. The econometrician first recovers factor exposures $\beta_{i k}$ for all return factors $k$ via stock-by-stock time-series regressions of returns on factor realizations. She then regresses average effective half spreads $h_{i t}$ multiplied by traded volume $V_{i t}$ over market depth $d_{i t}$ on estimated betas to recover factor tail risks $\xi_{k t}$ for each cross section $t$.

This interpretation of $\xi_{k t}$ derives from a simple model of competitive liquidity provision. Holding constant the level of uninformed trading, liquidity providers quote larger spreads and fewer shares for high beta securities to offset greater expected losses from being adversely selected on extreme factor moves. The difference in spreads across securities with different factor exposures increases with the anticipated factor jump arrival intensity and magnitude, but only for jumps large enough to cause picking-off losses by pushing latent security prices outside the quoted best bid and offer. Allowing uninformed volume to differ across stocks, spreads can be high because risk is high or because benign, risk-offsetting volume is low. Bid-ask spreads and depth thus must be normalized

\footnotetext{
${ }^{1}$ I use the term "market maker" to encompass all market liquidity providers rather than designated market makers (DMMs) alone. Equity market makers differ from traditional securities dealers in operating competitively in limitorder markets, but the name continues to be used to describe modern liquidity providers. For example, KCG Holdings, one of the world's largest liquidity providers in stocks by share volume, refers to itself as a market maker even for its non-DMM roles (https://www.kcg.com/market-making).

${ }^{2}$ Partly as a result of continual market-maker quote revisions, the ratio of order volume to trading volume typically exceeds 30 for U.S. stocks and 500 for U.S. exchange-traded products (Market Information Data Analytics System, http://www.sec.gov/marketstructure/datavis/ma_overview.html). Exchange-traded products are defined as CRSP securities with share code 73 and primarily consist of exchange-traded funds.
} 
to reflect the amortization of picking-off losses over uninformed volume. Combining these features, it follows that the cross-sectional slope of the liquidity composite $V h / d$ with respect to factor loadings represents the tail expectation of the distribution of potential factor jumps at date $t .{ }^{3}$ To the best of my knowledge, this insight represents the first use of liquidity measures to recover information about risks associated with standard return factors.

To facilitate exposition, I have assumed in this example that picking-off risk is the sole source of the bid-ask spread. The primary threat to my analysis is the inventory and non-jump adverse selection risks that belie this assumption. Equilibrium spreads must account for market maker compensation for carrying positions or trading against informed counterparties. For individual assets, including factor-mimicking ETFs, distinguishing among these sources of variation is difficult or impossible. By contrast, these alternative sources of variation must align with factor betas to contaminate tail risk estimates in my methodology. Section V.B verifies empirically that such contamination does not occur. To rule out contamination by inventory risk, I rerun my primarily analysis using the adverse selection component of the bid-ask spread in place of the effective spread under the identifying assumption that this component of the spread is unrelated to inventory risk. To rule out contamination by non-jump adverse selection, I include controls for a commonly used measure of "slow" adverse selection, the probability of informed trading, or PIN (Easley and O'Hara (1992); Easley, Kiefer, O'Hara and Paperman (1996)). Implied market tail risks are nearly identical to the baseline specification in both analyses.

An important difference between my approach and Fama-MacBeth cross-sectional regressions is that the researcher estimates expectational variables for tail risks rather than stochastic slope realizations. Like options prices, which represent a risk-neutral expected payoff, spreads incorporate expectations of potential tail risks, and the cross section of spreads delivers an expected cost of extreme realizations for each time interval rather than a realized cost. Consequently, coefficient estimates for anticipated extreme event risks $\xi_{k t}$ are much more precise than analogous risk prices in a Fama-MacBeth framework, and cross-sectional slopes are of independent interest as conditional

\footnotetext{
${ }^{3}$ Spreads and volume are both essential ingredients of the liquidity composite. The Internet Appendix considers spreads and volume as separate dependent variables and shows that cross-sectional slopes are often negative, i.e., higher beta stocks have lower spreads.
} 
factor risks rather than as inputs to a single unconditional tail risk estimate.

The recovered high-frequency market tail risk series aligns well with measures of anticipated and realized jump tails. The correlation with weekly left jump tail estimates from options data (Bollerslev and Todorov (2014)) exceeds 75\%, and a one standard deviation increase in the jump tail measure is associated with 4 more medium-scale jumps per hour (t-statistic of 7.4). In addition, the extracted tail-risk measure correlates strongly with the CBOE S\&P 500 implied volatility index (VIX), a 30-day forward volatility measure, and realized return variation on the SPDR S\&P 500 ETF (SPY), in part because both series feature significant comovement with realized jump intensities. Importantly, my measure predicts near-term tail realizations controlling for these measures and for the volume-synchronized probability of informed trading (VPIN) measure of Easley, López de Prado and O'Hara (2012).

In addition to providing a real-time barometer of market-factor risks, the measure performs well across diverse and challenging economic environments. I apply the methodology to the May 6, 2010 Flash Crash as a prototypical large and plausibly unexpected systematic jump. Existing tail estimation techniques do not have sufficient resolution to anticipate the Flash Crash or to reliably distinguish changes in tail risk ex post. Consequently, regulators possessed little ability to intervene until long after the event concluded because they lacked reliable tools for evaluating and responding to near-term catastrophe risks.

My measure helps to fill this gap by providing intraday assessments of tail risks. My tail risk measure is a natural leading indicator for liquidity crashes because it draws directly from liquidity providers' revealed expectations for jump tail events. For this event, the implied market tail risk increases several standard deviations relative to its value two days before an hour before the Flash Crash begins, 20 standard deviations in the quarter hour before the Flash Crash begins, and a remarkable 99 standard deviations at the height of the event. By contrast, realized volatility and implied idiosyncratic tail risk (corresponding with level changes in spreads) meaningfully increases only as the crash develops, suggesting that market makers correctly anticipated a liquidity crisis in the market factor and only later adjusted spreads to accommodate liquidity spillovers uncorrelated with the SPY market index. Incidentally, the only other occasions that register at least a 16 standard 
deviation increase in tail risk also correspond with extreme market factor realizations: the largest stock market decline in four years and the rollout of the NYSE's Phase IV Hybrid Market (February 27, 2007); the market plunge at the height of the "Quant Quake" of August 2007 (August 9, 2007); the U.S. House's rejection of Paulson's financial stabilization plan (September 29, 2008); and the S\&P downgrade of the U.S. federal government credit rating (August 5, 2011).

The Flash Crash also serves as an example of the dual uses of my measure; in addition to utilizing it as a forward-looking indicator, I apply the tail risk measure retrospectively to assess whether market makers register persistently elevated crash fears after the event. Both market and idiosyncratic anticipated jump risks quickly revert to pre-Crash levels and are statistically indistinguishable from the pre-Crash period after the ensuing weekend. This analysis serves as a first step toward an assessment of permanent impacts of liquidity-driven market meltdowns.

I next exploit the methodology's new intraday resolution on conditional tails to document the evolution of tail risks around major scheduled macroeconomic news. I show that anticipated jumps vary throughout Federal Open Market Committee (FOMC) announcement days in regular patterns of decreased tail risk (relative to non-announcement days) prior to the announcement, heightened tail risk in the quarter hours before and containing the announcement, and slightly elevated tail risk after the announcement. This finding suggests that the pre-FOMC announcement drift documented by Lucca and Moench (2015) and the anomalous performance of the CAPM documented by Savor and Wilson $(2013,2014)$ cannot be rationalized by unobserved market jump risk without concurrent time variation in risk premia.

Finally, I demonstrate that the methodology separately identifies tail risks in a multifactor setting, even when candidate factors are very highly correlated. For this purpose, I study the coevolution of aggregate market and financial sector risks during the 2007-2008 Financial Crisis. Despite the Financial Select Sector SPDR ETF (XLF) having an annual average daily correlation of $89 \%$ with the SPY over this period, differences in factor loadings in the cross section nonetheless enable precise estimates for anticipated shocks specific to the financial sector. The most extreme changes in the time series of financial sector tail risks often differ from those of the market jump series and correspond with major uncertainty innovations specific to financial firms, e.g., bank 
nationalization rumors and congressional votes on Fannie Mae and Freddie Mac rescue packages. The methodology thus offers a unique and useful tool for understanding the 2007-2008 Financial Crisis and assessing ongoing sector risks. Incidentally, this application provides a novel link between Brunnermeier and Pedersen (2009)'s concepts of market and funding liquidity by using market intermediaries' behavior to inform on fears of extreme disruptions to banks and the financial sector.

\section{Related Literature}

\section{A. Tail-Risk Measurement}

The primary objective of this study is to develop a forward-looking measure of instantaneous tail risk for a variety of return factors. Similarly to Kelly and Jiang (2014), this paper takes a cross-sectional approach to obtain conditional tail risk estimates. Kelly and Jiang (2014) show that the aggregate market tail inherits individual asset tail dynamics if asset return tails follow a power law. If tail realizations are not too infrequent, this cross-sectional approach can detect physical market-factor tail shapes with short panels on the order of one month. My approach differs in two key respects. First, my estimation strategy relies on spreads rather than on tail return realizations. Because every bid-ask spread is informative at all times rather than only in the "rare event" states associated with extreme returns, I significantly increase the conditioning frequency at which tail risk estimates can be constructed. Second, my measure recovers tail expectations, which jointly summarize factors' ex ante tail position and shape, rather than the realized tail shape beyond a time-varying threshold value. As an example of this distinction, Kelly and Jiang (2014)'s timevarying tail threshold increases sharply during the 2007-2008 Financial Crisis, and the implied tail shape looks no more extreme than during the preceding years as a result.

The two prevailing alternatives for tail risk measurement take advantage of options panels or of high-frequency time series for individual securities. The most closely related work in this literature is Bollerslev and Todorov (2014), which uses a cross section of S\&P 500 index options to recover timevarying jump tails. In so doing, the authors exploit the fact that differential exposure to jump risk is the key source of variation in prices of close-to-maturity deep out-of-the-money options. Likewise, this paper makes use of the insight that differential exposures to jump risk drive variation in the 
size of (volume-adjusted) bid-ask spreads - themselves interpretable as prices of very short-dated options (Copeland and Galai (1983)) — across stocks with different factor betas.

Bakshi, Kapadia and Madan (2003) consider skewness and kurtosis for systematic and idiosyncratic risks as implied by differential pricing of individual equity options. Bollerslev, Tauchen and Zhou (2009) estimate the variance risk premium in a model-free setup. Backus, Chernov and Martin (2011) recover the distribution of implied consumption disasters from options data. Options provide richer moneyness cross sections than bid-ask spreads, and for this reason, such options-based analyses can identify a distribution of potential risks whereas my approach cannot. Bollerslev and Todorov (2011a,b) supplement options analyses with high-frequency data and extreme value in-fill arguments to estimate jump tails for the aggregate market.

My methodology complements these approaches. This paper adds the ability to estimate tail risks (1) in the very near term, (2) for a broad set of factors, (3) with high-frequency conditioning, and (4) under alternative sets of assumptions. Options-based approaches have difficulty assessing near-term risks because option maturities are long relative to intraday or daily events, ${ }^{4}$ and many options on individual names are too illiquid to be used for recovering non-market factor information. Likewise, combining realized jumps with extreme value theory can only recover very slow-moving variation in jump tails, and it is not yet applicable to candidate factors not directly traded in liquid factor-mimicking securities (e.g., size, value, and momentum). Conversely, my approach is limited in not being able to describe the full distribution of potential jump events or to gauge the persistence of negative shocks in a forward-looking way.

\section{B. Market Microstructure}

The key relation between spreads and tail risks emerges from Budish, Cramton and Shim (2015)'s model of high-frequency market making in the presence of picking-off risk. I augment their model by imposing a factor structure on the jump process and by considering the resulting cross section of spreads across multiple assets. Forerunners in developing this source of risk include Copeland and Galai (1983), Harris and Schultz (1997), and Foucault, Röell and Sandås (2003), among others.

\footnotetext{
${ }^{4}$ Even Carr and $\mathrm{Wu}(2003)$ filters out options with time to maturity less than one week, and their important study explicitly focuses on option price dynamics as time to maturity goes to zero.
} 
Indeed, the equilibrium condition of Budish et al. (2015) and this study can also be motivated using the quotes-as-options framework of Copeland and Galai (1983). Viewed from this perspective, bidask spreads naturally extend short-dated options to the near-instantaneous expiration horizons that are especially well-suited for isolating jump risks (Bollerslev and Todorov (2011b)).

Many other works investigate the information content of the limit order book. Of this set, Foucault, Moinas and Theissen (2007) is closest to this paper in showing that limit order books contain volatility information in addition to directional information, albeit for individual assets.

This paper also shares the spirit of Nagel (2012) in relating returns to intermediation to forwardlooking market volatility. Specifically, Nagel (2012) shows that short-term reversal returns are highly correlated with the VIX, and he interprets this relation as evidence that financially constrained intermediaries are less able to provide liquidity in bad economic times. I derive a similar relationship between intermediary behavior and the VIX with picking-off risk as the central driver. When anticipated jump risks - a component of the VIX - are higher, the required return to intermediation is higher and the cross-sectional slope of bid-ask spreads with respect to factor exposures is steeper. By contrast with time-varying tail risk, Nagel (2012)'s constrained-intermediary mechanism has less bite at high frequencies or for non-market factors considered in this paper.

A key contribution of this work is to extend this intuition to a broad set of factor risks and show that bid-ask spreads embed rich information about the underlying structure of asset returns. In this sense, my paper also relates to the broad literature on common factors in liquidity and trading volume (e.g., Chordia, Roll and Subrahmanyam (2000), Lo and Wang (2000), Hasbrouck and Seppi (2001), and Korajczyk and Sadka (2008)). Prior work such as Lo and Wang (2000), Hasbrouck and Seppi (2001), and Cremers and Mei (2007) also recover common factors in volume and liquidity measures, but these factors differ from realized or excess return factors typically studied in the asset pricing literature. 


\section{Spreads and Asset-Pricing Risks}

\section{A. Picking-Off Risks and Return Tails}

The investible universe consists of $N$ securities indexed by $i$. The fundamental value of each asset evolves as a compound Poisson process with arrival-rate parameter $\lambda_{i, j u m p}$ and jump distribution $F\left(J_{i}\right)$. By contrast with continuous variation in prices, jumps represent large, discontinuous changes in asset value over an infinitesimal interval. All market participants observe a public news source on each asset's value. Many important intraday news events, e.g., Federal Open Market Committee announcements, share these properties. ${ }^{5}$

The economy consists of two types of traders: uninformed liquidity consumers with unit demands for a specific asset and a continuum of potential market makers, each capable of offering one unit of liquidity in a single asset. Market makers "race" to enter the limit-order book to intermediate for the liquidity consumer at a price $h_{i}$, the half-spread. The order book respects price-time priority, although queuing order is random from the perspective of market makers. Potential market makers that lose the speed race to intermediate at $h_{i}$ instead participate as stale-quote "snipers"-if the underlying value of the asset jumps outside of the quoted prices given by the National Best Bid and Offer (NBBO), the fast non-market makers consume liquidity for a profit of $J_{i}-h_{i}$ at the offering market maker's expense. $h_{i}$ is set by price competition among competitive market makers.

The timeline of events is as follows. At time 0 , the first race commences among potential market makers of equal speed. The winners in each asset are selected at random, e.g., by noise in the exchange clock. Time then advances until either of two events occurs to force an update to the limit order book. One possibility is that an information event occurs that induces a jump in an underlying asset value. The fringe of stale quote snipers trade with the resting market maker if the jump exceeds the half-spread for the affected assets. Subsequent orders conditioning on the new information set establish a new bid and offer. Alternatively, a fundamental trader arrives and takes available liquidity from the order book. In this scenario the market maker earns the half-spread $h_{i}$, and the set of potential market makers again race to refill the order book centered at the same price

\footnotetext{
${ }^{5}$ The sudden arrival of previously embargoed news should not be conflated with known release times. I treat the case of fixed arrival times (and violations of this Poisson assumption) in the Internet Appendix.
} 
as before. Because the book refreshes in both event categories, the market making sector's optimal policy for liquidity provision entails providing exactly one unit of liquidity and replenishing it if and only if liquidity is taken.

Figure I illustrates the sources of market-maker profits and losses per unit of offered liquidity. The rate of gains from intermediation equals the half-spread $h$ multiplied by the arrival rate of liquidity consumers $\lambda_{F T}$ (I suppress subscripts for clarity). The probability of this event for a particular unit of liquidity is $\lambda_{F T} /\left(\lambda_{F T}+\lambda_{j u m p}\right)$. The expected costs from being picked off equal the arrival rate of jumps in the fundamental value of the asset $\lambda_{j u m p}$ multiplied by the tail expectation of jump sizes $J$ above the spread $h$, as taking liquidity is desirable only when the price movement exceeds the half-spread. Equating these quantities obtains the equilibrium condition of Budish et al. (2015):

$$
\underbrace{\lambda_{F T} \times h}_{E[\text { benefit } / \text { time }]}=\underbrace{\lambda_{\text {jump }} \times \operatorname{Pr}(J>h) \times E[J-h \mid J>h]}_{E[\text { cost } / \text { time }]} .
$$

Equation (1) relates anticipated price movements $J$ to the half-spread $h$ at each date $t$ (both in percent). Higher arrival rates of liquidity consumers drive spreads toward zero, whereas faster information arrivals or larger jumps conditional on information arrivals increase $h$. Focusing on costs, only underlying price movements larger than $h$ result in costs to the market maker in trading at unfavorable prices.

The model thus far supposes that desired trading volume is fixed at one unit. However, even traders engaged in order splitting frequently trade larger quantities in a single order, and pickingoff strategies routinely execute against many or all of the orders available at a given price. It is therefore essential to incorporate into the model non-unit liquidity demands and quoted depths, or quantities available to buy or sell at given prices as indicated by the order book.

In the baseline model, the expected benefit of intermediating a (unit) order exactly offsets the expected cost of providing the option to trade to stale-quote snipers. Adjusting Equation (1) for variable quantities of liquidity demanded and supplied, market makers' expected benefit per unit 
time of facilitating trade for a stochastic quantity $q$ and an offered depth $d$ becomes

$$
\lambda_{F T} \times h_{i} \times(d+(E[q \mid q<d]-d) \operatorname{Pr}(q<d)) .
$$

The new parenthetical term encapsulates the expected amount of liquidity consumed given a bid or offer size $d$. Market makers only intermediate for desired trade sizes up to $q=d$. Beyond that point, larger liquidity demands instead convert into resting limit orders or "walk the book" to consume liquidity at higher prices, for which a different equilibrium condition applies.

By contrast, the expected cost of offering $d$ shares increases linearly in $d$ without bound, as the mass of stale-quote snipers picks off the entire offered depth when given the opportunity. The net benefit per share of depth quoted is thus weakly decreasing in $d$, because fundamental traders do not always consume up to $q=d$ units of liquidity, whereas arbitrageurs do.

If queue positions are known, market makers earn positive rents on inframarginal units, and market makers (or orders) toward the back of the book are closer to break-even in expectation. However, in high-frequency settings, continual churn in the limit order book makes position order difficult to track (Yueshen (2014)). In the limit of random sequencing, all units of liquidity offered satisfy a depth-adjusted equilibrium condition of Equation (1) in which each unit of depth quoted incurs the NBBO-average liquidity costs and benefits,

$\lambda_{F T} \times h \times \underbrace{\{E[q \mid q<d] \times \operatorname{Pr}(q<d)+d \times \operatorname{Pr}(q \geq d)\}}_{\equiv q^{*}} \times \frac{1}{d}=\lambda_{\text {jump }} \times \operatorname{Pr}(J>h) \times E[J-h \mid J>h]$,

where $q^{*}$ is the expected quantity intermediated for fundamental traders.

This adaptation for non-unit quantities also addresses distortions wrought by minimum tick sizes and discrete price increments. Forcing the half-spread to exceed the expected cost of providing a single unit of depth attracts additional market makers because the price of liquidity provision is artificially high. In turn, competitive liquidity providers respond by adding quotes to the order book until the total depth at the NBBO equates expected intermediation gains and picking-off costs as in Equation (3). ${ }^{6}$

\footnotetext{
${ }^{6}$ In principle, exploiting the shape of the order book provides additional information on the distribution of factor
} 
Armed with Equation (3), I now relate market maker liquidity provision to the factor structure in jump returns. Jumps in the value of an asset arise from common factor or idiosyncratic jumps. I decompose these innovations in each asset's fundamental value as

$$
r_{i}^{d}=\sum_{k} \beta_{i k} r_{k}^{d}+\tilde{r}_{i}^{d}
$$

for a set of return factors $k$ and idiosyncratic jump return $\tilde{r}^{d}$. Such high-frequency factor structures have strong empirical support and are the basis for an active literature on high-frequency covariance estimation and jump regressions (e.g., Todorov and Bollerslev (2010), Li et al. (2014), Aït-Sahalia and Xiu (2015), and Bollerslev et al. (2016)).

I make two simplifying assumptions to facilitate taking the adapted model to the data:

Assumption 1. Jump arrivals are independent both among factors and between factors and idiosyncratic discontinuous returns.

Assumption 2. Idiosyncratic jumps are distributed i.i.d. across assets.

Both assumptions streamline the estimation procedure but are otherwise inessential. Assumption 1 excludes co-jumps and more complex jump dependencies among factors. Whether excluding co-jumps is reasonable depends on whether the considered return factors are plausibly orthogonal to one another. Relaxing this assumption to allow for co-jumps is readily accommodated by adding cross terms to each cross-sectional estimation, as described in Appendix B. Assumption 2 excludes heterogeneity in the rate of idiosyncratic information arrival among assets. This assumption, too, may be relaxed, for example by estimating security loadings on the common factor in idiosyncratic volatility - "CIV" of Herskovic, Kelly, Lustig and Nieuwerburgh (2016) - under the assumption that such factor loadings extend also to idiosyncratic jumps. In the Internet Appendix, I control for idiosyncratic risks using idiosyncratic volatility and idiosyncratic volatility factor loadings, and my tail risk estimates are virtually unchanged in both cases.

jump risks. Other liquidity providers may offer more depth at larger spreads. These traders balance expected intermediation gains after depth at the NBBO is exhausted against expected jump costs conditional on the price jump exceeding their price of liquidity $h^{\prime}>h$. 
By assumptions 1-2, the jump intensity for stock $i$ is given by

$$
\lambda_{\text {jump }}=\sum_{k} \lambda_{k}+\tilde{\lambda}
$$

where $\lambda_{k}$ is the jump intensity for factor $k$ and $\tilde{\lambda}$ is the jump intensity for the stock's idiosyncratic component. This representation decomposes short-lived adverse selection risks into factor- and idiosyncratic-news components.

Picking-off costs to the market maker integrate across the joint distribution of potential jumps larger than the half spread. By excluding co-jumps, when a factor $k$ jumps, discontinuous returns have a simple form, $r_{i}^{d}=\beta_{i k} r_{k}^{d}$, as coincident jump returns from other sources are exactly zero. Consequently, we can sum over costs associated with each factor independently rather than integrating over the region associated with all potential combinations of jump returns. Substituting Equations (4) and (5) into Equation (3) delivers:

$$
h \lambda_{F T} \frac{q^{*}}{d}=\sum_{k} \lambda_{k} \int_{h / \beta_{k}}^{\infty}\left(\beta_{k} r_{k}-h\right) f\left(r_{k}\right) d r_{k}+\tilde{\lambda} \int_{h}^{\infty}\left(\tilde{r}_{i}-h\right) f\left(\tilde{r}_{i}\right) d \tilde{r}_{i} .
$$

The salient region of the jump distribution for each asset-factor combination is determined by $h / \beta_{k}$. For each factor $k$, jump risks can be decomposed into two regions: jumps larger than the half-spread for all assets, i.e., $r_{k} \geq \bar{h}_{k} \equiv \max _{i}\left(h_{i} / \beta_{i k}\right)$, and jumps larger than the half-spread for some assets but not for others:

$$
\begin{aligned}
\int_{h_{i} / \beta_{k}}^{\infty}\left(\beta_{i k} r_{k}-h_{i}\right) f\left(r_{k}\right) d r_{k} & =\int_{h_{i} / \beta_{i k}}^{\bar{h}_{k}}\left(\beta_{i k} r_{k}-h_{i}\right) f\left(r_{k}\right) d r_{k}+\int_{\bar{h}_{k}}^{\infty}\left(\beta_{i k} r_{k}-h_{i}\right) f\left(r_{k}\right) d r_{k} \\
& =\beta_{i k} \underbrace{\int_{h_{i} / \beta_{i k}}^{\bar{h}_{k}} \bar{F}\left(r_{k}\right) d r_{k}-\bar{h}_{k} \bar{F}\left(\bar{h}_{k}\right)}_{\text {small jumps }}+\beta_{i k} \underbrace{\infty}_{\text {large jumps }} r_{\bar{h}_{k}} f\left(r_{k}\right) d r_{k}
\end{aligned}
$$

where $\bar{F}$ denotes the counter-cumulative distribution function for $r_{k}$.

I assume that all jumps are large relative to half-spreads for my set of assets. In support of this assumption, Hendershott, Jones and Menkveld (2011) show that by 2004, the first year in my sample, the effective half-spread for smaller-than-average (fourth size quartile) stocks is less than 6 
basis points; using a $\beta$ cutoff of 0.5 implies the smallest "large" jump can be less than a 12 basis point change in price, or equivalently, less than an 8-22 cent change in the price of the SPY market proxy during the time period considered. By contrast, the smallest (median) realized jumps detected in the SPY by the Lee and Mykland (2008) and Bollerslev et al. (2013) methodologies are 26.5 (46.6) basis points and 13.5 (32.7) basis points, respectively. ${ }^{7}$ In estimation, I also impose loose restrictions on the set of assets considered to exclude stocks with extreme spreads and beta loadings to ensure that this assumption holds. ${ }^{8}$

Excluding "small" jumps delivers the following simplifying relation:

$$
\lim _{\bar{h}_{k} \downarrow 0} \int_{h_{i} / \beta_{k}}^{\infty}\left(\beta_{i k} r_{k}-h_{i}\right) f\left(r_{k}\right) d r_{k}=-h_{i}+\beta_{i k} \int_{0}^{\infty} r_{k} f\left(r_{k}\right) d r_{k}
$$

Equation (6) then reduces to a linear relation between the liquidity consumer arrival rate for each asset and the distribution of jump risks for each factor multiplied by the asset's factor exposure:

$$
\begin{aligned}
h \lambda_{F T} \frac{q^{*}}{d} \stackrel{(4),(5)}{=} & \sum_{k} \lambda_{k} \int_{h / \beta_{k}}^{\infty}\left(\beta_{k} r_{k}-h\right) f\left(r_{k}\right) d r_{k}+\tilde{\lambda} \int_{h}^{\infty}(\tilde{r}-h) f(\tilde{r}) d \tilde{r} \\
& \stackrel{(8)}{=} \quad-\left(\tilde{\lambda}+\sum_{k} \lambda_{k}\right) h+\sum_{k} \beta_{k} \lambda_{k} \int_{\bar{h}_{k}}^{\infty} r_{k} f\left(r_{k}\right) d r_{k}+\tilde{\lambda} \int_{h}^{\infty} \tilde{r} f(\tilde{r}) d \tilde{r},
\end{aligned}
$$

which implies

$$
\underbrace{\left(\lambda_{F T} q^{*}+\lambda_{\text {jump }} d\right)}_{\equiv \bar{V}} \frac{h}{d}=\sum_{k} \underbrace{\lambda_{k} E\left[r_{k}^{d} \mid r_{k}^{d}>\bar{h}_{k}\right]}_{\equiv \xi_{k}} \beta_{k}+\underbrace{\tilde{\lambda} E\left[\tilde{r}^{d} \mid \tilde{r}^{d}>\bar{h}\right]}_{\equiv \tilde{\xi}} .
$$

The left-hand side of Equation (9) represents a liquidity composite of normalized half-spreads $h / d$ and the volume-weighted arrival rate of both trader types, $\bar{V}=\lambda_{F T} q^{*}+\lambda_{j u m p} d$. The coefficient on each $\beta_{k}, \lambda_{k} E\left[r_{k} \mid r_{k}>\bar{h}_{k}\right]$ or $\xi_{k}$, represents the tail risk for factor $k$. Faster event arrival rates or more damaging potential events must be compensated in equilibrium by higher anticipated trading

\footnotetext{
${ }^{7}$ Jump detection tests compare five-minute returns against estimates of local volatility. I use a $1 \%$ significance threshold in the Lee and Mykland (2008) methodology and $\tau=4$ standard deviations in the Bollerslev et al. (2013) methodology. Corresponding values for the Financial Select Sector SPDR ETF (XLF) are 18.2 (60.7) and 12.5 (37.4) basis points.

${ }^{8}$ Empirically, I find that parameter estimates vary little with the choice of threshold $\bar{h}_{k}$ for market (SPY) and financial sector (XLF) test factors.
} 
revenues $\bar{V} h$.

\section{B. Cross-Sectional Recovery of Tail Risks}

Estimating tail risks from Equation (9) takes place in two stages. First, the econometrician computes betas with respect to candidate realized return factors. I estimate backward-looking, rolling annual betas using daily returns $r_{i t}$ on candidate factor realizations $f_{k t}$ for each stock in the filtered sample $i$ :

$$
r_{i t}=\alpha_{i}+\sum_{k} \beta_{i k}^{(t)} f_{k t}+\epsilon_{i t}, \forall i
$$

Armed with these betas, I estimate (symmetric) tail risks cross-sectionally across stock-level observations via least absolute deviations regression:

$$
\left(\frac{V h}{d}\right)_{i t}=\tilde{\xi}_{t}+\sum_{k} \xi_{t k} \beta_{i k}+\delta_{i t}
$$

For much of the ensuing analysis, all variables (and products of variables, where appropriate) are hourly averages over the respective time interval. $d$ is the bid and offer depth summed across exchanges in shares. $V$ is realized volume divided by two to account for half of volume being buys or sells, on average. ${ }^{9}$ I treat realized volume as an unbiased, but noisy proxy for the volume expected by liquidity providers. $h$ is the effective half-spread. The quoted spread sometimes overstates the true cost of consuming liquidity, as trades may execute inside the (displayed) spread. $\delta_{i s}$ is a stockspecific error term for date $t$. $\xi_{t k}$ represents the average anticipated jump risk over the interval

for factor $k$. The time fixed effect $\tilde{\xi}_{t}$ controls for common movements in asset-level tail risk not associated with the market factor or other return factors.

Equations (10) and (11) resemble Fama-MacBeth regressions for determining prices of factor risk. They differ in that all $\xi_{t}$ estimates are of independent interest rather than only inputs into a single time-series average value. Unlike the realized factor premium at each date, the ex ante expected jumps are not (conditionally) stochastic, and their estimation relies on large $N$ rather than on large $T$ asymptotics. The key assumption needed for inference on each $\xi_{t}$ term is that

\footnotetext{
${ }^{9}$ Using signed volume techniques such as Lee and Ready (1991) has minimal effect on results in most instances, as detailed in the Internet Appendix.
} 
factor loadings $\beta$ estimated over the prior year are valid for the subsequent trading day. The choice of annual betas trades off accuracy for precision in factor-loading estimates, but differences between betas for different horizons are likely to be small.

Equation (11) also clarifies the conditions under which other sources of the bid-ask spread are potentially problematic. To the extent that inventory risk and non-jump adverse selection risk influence effective spreads, Equation (11) implies that these drivers distort tail risk estimates $\xi_{k}$ if and only if they are cross-sectionally correlated with factor loadings $\beta_{k}$. Otherwise, these terms act as measurement error on the left or a level shift in the "idiosyncratic" tail risk estimate $\tilde{\xi}$.

More positively, Equation (11) encapsulates the robustness of my methodology to unexpected liquidity demands or manipulative liquidity supply at the single-security level. ${ }^{10}$ Consider, for example, a large portfolio liquidation that surprises market makers with unexpected trading volume. The composite liquidity measure $V h / d$ increases for the affected securities, but factor tail risk estimates $\xi_{t k}$ remain constant unless the unexpected liquidation impact to $V h / d$ aligns with factor exposures, e.g., a stock with a market beta of two is sold twice as aggressively as a stock with a market beta of one. Even allowing for such trading behavior, distortion of $\xi_{t k}$ estimates requires liquidation of a large number of stocks simultaneously in precisely this manner. Similarly, quote stuffing, spoofing, or other order book manipulations may affect $V h / d$ for individual assets, but influencing implied factor tail risks is much more difficult because strategies must influence a large set of stocks' liquidity composites in line with their factor exposures.

For estimation, I use median regression rather than OLS in the second-stage regressions because occasional extreme observations contaminate the cross section of the liquidity composite $V h / d$. Such outliers are caused by data recording errors and departures from the model. These observations otherwise result in too much weight being placed on fitting a small number of influential points with extreme volumes or spreads. However, employing this robust regression approach compounds the problem of using estimated rather than known betas from the first stage. Direct corrections to standard errors (as in Shanken (1992)) are unavailable for this hybrid approach, and the discontinuous

\footnotetext{
${ }^{10}$ The Internet Appendix investigates tail risk implied by variation in liquidity of the SPY. The results therein suggest that SPY-implied tail risk is typically a noisy version of cross-section implied tail risk. However, in studying the 2010 Flash Crash, I find that the simpler $\xi_{M K T}^{S P Y}$ measure breaks down precisely when a tail risk measure is most necessary.
} 
moment conditions associated with quantile regression make GMM numerically intractable.

Instead, I compute standard errors via pairs bootstrap to resolve the generated regressors problem with a median regression second stage. The bootstrap enables straightforward construction of standard errors in settings with complicated dependence across regression stages and calendar time. This procedure first uses the full sample of stocks and 252 rolling trading days to obtain point estimates for $\xi_{t k}$. Then, for each replication $r=1, \ldots, R$, I construct resampled coefficient estimates $\xi_{t k}^{(r)}$ as follows:

1. For each stock $i=1, \ldots, N$, draw with replacement 12 strings of 21 trading days during the 252 trading days preceding date $t$;

2. Estimate $\beta_{i k}^{(r)}$ for all stocks $i$ using Equation (10);

3. For each time interval on date $t$, draw $N$ stocks with replacement from the set of $N$ stocks;

4. Estimate $\xi_{t k}^{(r)}$ using Equation (11) on the $N$ randomly chosen stocks.

Asymmetric confidence intervals for $\xi_{t k}$ are constructed directly from quantiles of $\xi_{t k}^{(1)}, \ldots, \xi_{t k}^{(R)}$ for $R=1000$ resamples. I use strings of 21 trading days as bootstrap blocks to account for potential serial correlation in errors in Equation (10). The bootstrap hence simultaneously accounts for uncertainty in betas by resampling over time and in tail risk estimates by resampling over stocks and their generated betas.

\section{Data}

The primary data sources for this study are the Center for Research in Security Prices (CRSP) U.S. Stock Database and the New York Stock Exchange Trade and Quote (TAQ) data. The TAQ data aggregate orders from all Consolidated Tape Association exchanges and are timestamped to the second. I follow Holden and Jacobsen (2014) to recover cleaned effective spreads and market depths from the underlying TAQ data. Traded volume over each interval is directed observed. CRSP provides security attribute data (e.g., share codes), unique ticker-entity mappings, and daily shares outstanding for each security. In addition to CRSP and TAQ, I obtain intraday historical Chicago Board Options Exchange Volatility Index (VIX) data from Pi Trading. 
The main data sample consists of all common stocks (CRSP share code $=10$ or 11$)$ in the TAQ database from January 2005 to December 2013. Although the TAQ database starts in 1993, three features of this early data complicate analysis. First, the assumptions of continually updated spreads and minimal order processing costs are not plausible until algorithmic trading improvements in the mid-2000s (Foucault, Röell and Sandås (2003)). Second, the key zero-expected profit condition of Equation (1) likely does not apply to specialist or collusive market making characterizing earlier years (see, e.g., Christie and Schultz (1994)). By contrast, free entry is a critical dimension by which algorithmic market making differs from specialist market making (Hendershott et al. (2011)). Free entry not only makes the breakeven condition more likely to hold, but it also encourages the collection of new signals. More sophisticated market makers sharpen the adverse selection faced by less-informed intermediaries because the latter group becomes the marginal liquidity providers exactly when order flow is most unfavorable (Han, Khapko and Kyle (2014)). Third, the free inflow of opportunistic liquidity providers likewise alleviates the collective capital constraints faced by intermediaries. Consequently, inventory risk is less likely to be a key factor in determining liquidity prices than for the NYSE specialists studied by Comerton-Forde, Hendershott, Jones, Moulton and Seasholes (2010). Notwithstanding these concerns, I also consider 2004 in summary plots to illustrate the potential breakdowns of my measure for pre-HFT liquidity provision.

I restrict the sample to exclude the 15 minutes after market open and before market close. These periods are characterized by unusual trader composition and informational events, such as elevated informed trading activity at market open in response to overnight events. For much of my analysis, I split the remainder of the trading day into six hourly bins running 9:45-10:45am through 2:45-3:45pm. The filtered sample consists of roughly 2,800 stocks for each hour of each trading day from 2004 to 2013. Additional data cleaning and filtering details are provided in Appendix A.

\section{Results}

My empirical analysis proceeds in two main steps. In the first step, I recover hourly tail risk estimates for a one-factor market model and compare these estimates to market tail realizations and to alternative near-term forecasts such as the VIX. In the second step (Section VI), I apply the tail 
risk extraction methodology to verify the performance of the jump tail measure for the 2010 Flash Crash, major macroeconomic news events, and the 2007-2008 Financial Crisis. This last example demonstrates the power of the two-stage procedure for separately identifying factor tail risks in a multifactor setting.

Figures II and III plot recovered market tail risks by hour over the 2004 to 2013 sample period. Figure II plots monthly rolling means of $\xi_{M K T}$ to emphasize low-frequency variation in tail risk. Reassuringly, spread-implied jump risk spikes relative to realized volatility during the financial crisis and global recession, a time of extreme market risks. Confidence intervals are tight enough to ensure that market tail risk is statistically distinguishable from zero throughout the sample. This feature reflects the value of exploiting large cross sections for identifying conditional risks.

Figure III illustrates the jump tail measure's ability to capture market news in real time. I mark the fifteen largest changes in implied market risks over the preceding 24 hours in green. I compute changes by differencing jump tails for the same hour at date $t$ and $t-1$ to account for intraday patterns and news that spans multiple trading hours, and I separate increases by a minimum distance of 10 trading days to isolate distinct events. The extracted set of events consists primarily of scheduled Fed-affiliated and macroeconomic announcements. Scheduled and surprise events are captured "in progress" - for example, the 1:45-2:45pm window captures the typical timing of FOMC announcements, and the 2:45-3:45pm window on May 6, 2010 captures the Flash Crash.

Figure IV indicates that the tail risk measure also captures well-known intraday patterns in volatility and jump risks (e.g., Andersen and Bollerslev (1997), Bollerslev and Todorov (2011b)). The tail risk measures achieve extreme values in 2008 for every hour of the trading day, even relative to other crisis years, so I omit 2004 and 2008 from the plot to maintain resolution on the other years of the 2005-2013 period considered in empirical tests. Both plots rank 2007 to 2011 as among the most extreme years for expected jumps (left) and realized jumps (right) and 2005-2006 and 2012-2013 as the least extreme years. As with volatility, the pronounced skewed U-shape pattern manifests in tail risks for each year of the sample.

In addition to matching the shape of intraday patterns, the anticipated tail risk measure agrees in magnitude with realized jumps. Comparing panels of Figure IV, the anticipated tail risk measure 
implies similar discontinuous variation as is realized in medium-scale jumps. For example, the opening hour of 2009 features roughly 4.5 basis points of anticipated jump variation and 4.2 basis points of realized jump variation.

The magnitudes of my anticipated tail risk measure are also bracketed by estimates of realized S\&P 500 jump variation from prior work. Specifically, Table 9 of Huang and Tauchen (2005) reports average daily jump variation for the S\&P 500 cash index (S\&P 500 index futures) as 8.62 (9.53) basis points for 1997-2002, and Table 2 of Bollerslev, Todorov and Li (2013) reports average daily jump variation for S\&P 500 index futures as 20.1 basis points for 1997-2010. My sample average hourly tail risk is 1.59 basis points per hour; scaling this value by 6.5 hours per trading day obtains 10.3 basis points per day of jump variation. ${ }^{11}$

Although my study focuses on the time-series properties of the tail risk measure, each of these figures presents coefficients from new cross-sectional regressions of liquidity composites on factor risks. The cross-sectional regressions' $R^{1}$ has a mean (median) value of 0.0150 (0.0122) across all hour-days using the one-factor market model for jump returns. ${ }^{12}$ On one level, the low $R^{1}$ is unsurprising because realized volume is a coarse proxy for expected volume for individual securities, and the dependent variable hence suffers from measurement error unexplained by exposure to factor risks. However, inventory risks or classical adverse selection also may drive cross-sectional variation in the composite liquidity measure, and these other sources of the bid-ask spread contaminate estimated factor risks if the omitted variable is cross sectionally correlated with betas. Section V.B addresses this concern in depth.

\footnotetext{
${ }^{11}$ This simple rescaling likely understates the tail risk implied by my measure because the first and last 15 minutes of each trading day are omitted from my sample, and these are also the most volatile time periods. If the tail risk of the first and last quarter hours are equal to those of the first and last hours in my sample, this estimate increases to 10.7 basis points per day.

${ }^{12} R^{1}$ is the quantile regression analogue of $R^{2}$ (Koenker and Machado (1999)). Median regression selects the coefficients $\mathbf{b}$ that minimize the value $V=\sum_{i} \delta_{i}\left(0.5-\mathbf{1}\left(\delta_{i}<0\right)\right)$ for $\delta_{i}=y_{i}-\mathbf{x}_{i}^{\prime} \mathbf{b}$. Koenker and Machado (1999) suggest a goodness of fit criterion $R^{1}=1-V_{U} / V_{R}$ for an unrestricted coefficient vector $\mathbf{b}_{U}$ and a restricted coefficient vector $\mathbf{b}_{V}$ with only an intercept term. This criterion parallels $R^{2}=1-S_{U} / S_{R}$ for $S_{U}$ and $S_{R}$ equal to the sum of squared residuals in unrestricted and restricted least-squares models.
} 


\section{Relation to Other Tail Risk and Volatility Measures}

Table I relates my spread-implied tail risk measure to four other tail risk and volatility measures proposed in the literature: options-implied tail risks from Bollerslev and Todorov (2014); the VIX; hourly realized volatility; and the volume-synchronized probability of informed trading (VPIN) for E-mini S\&P 500 futures. $^{13}$ Daily and weekly values are equal-weighted averaged hourly values within each respective time bin.

All volatility and tail risk measures are highly positively correlated at the daily and weekly frequencies. The market tail risk measure comoves especially strongly with realized market volatility at the weekly frequency, which suggests that the crash risks relevant for market makers align well with longer-horizon volatility events. Relative to the options-implied tails, high-frequency spreadimplied tails are more similar to realized volatility and less similar to the VIX. This relationship is expected in that options-implied tails are "low frequency" (on the order of a week) and do not condition on intraweek information relevant to near-term volatility and jump tail risks. Likewise, the spread-based measure does not span the "long horizon" information captured in the monthly VIX that is embedded in options with more than a week to expiration. VPIN is roughly equally correlated with all measures at daily and weekly frequencies, and it becomes slightly less correlated with my tail risk measure at the hourly frequency. I show in Section V.A that this imperfect correlation translates into picking up distinct variation in explaining and forecasting jump realizations.

\section{A. Empirical Tests}

The key verification regression takes the following form for the market factor (and is later repeated for a financial sector proxy in Section VI):

$$
\begin{aligned}
\text { tail_realization } t_{t}= & \alpha+\beta \xi_{t-\Delta, M K T}+\gamma V I X_{t-\Delta}+\delta C V_{t-\Delta}+\zeta V P I N_{t-\Delta}+\alpha_{-1} \text { tail_realization }_{t-1} \\
& +\beta_{-1} \xi_{t-1-\Delta, M K T}+\gamma_{-1} V I X_{t-1-\Delta}+\delta_{-1} C V_{t-1-\Delta}+\zeta_{-1} V P I N_{t-1-\Delta}+\epsilon_{t} .
\end{aligned}
$$

\footnotetext{
${ }^{13}$ VPIN has been updated since its inception in Easley, López de Prado and O'Hara (2012). I use bulk volume classification with wide volume bars (10 buckets) as suggested by the classification accuracy tests of Easley, de Prado and O'Hara (2016). See Andersen and Bondarenko (2015) for additional discussion of several variants of VPIN.
} 
I measure tail realizations in units of spreads and basis points and in event counts and event sums (weighting by event size). Given the tail factor's close coevolution with other forward-looking variation measures, e.g., the VIX, I include the VIX as a control to ensure that the tail measure indeed has additional explanatory power for tail events. I also include total continuous variation $C V$ to isolate the contribution of the tail risk measure to explaining jumps rather than continuous variation. $C V$ is defined as the sum of squared minutely price movements smaller than 2.5 standard deviations of minutely price movements adjusted for time-of-day effects within each year (following the continuous and jump variation decomposition of Mancini (2009), among others, and Bollerslev et al. (2013)'s methodology specifically). ${ }^{14}$ Realized continuous variation comoves very strongly with jump variation, so including it as a control presents a particularly strong test of the interpretation of the recovered coefficients as an estimate of anticipated jump tails. Finally, I include the latest bulk-volume classified VPIN measure to distinguish the information content of my tail risk measure from a leading alternative.

The tail realization measures used in the regression are as follows. Basis-point jumps count the number of events in which the minutely midpoint return exceeds 10 basis points, my implicit "large jump" threshold. The jump sum is a weighted count of the number of events in which the minutely return exceeds 5, 10, 25, and 100 basis points, with respective weights of 5, 10, 25, and 100. Spread jumps count the number of occasions in which the minutely return exceeds 5 quoted half-spreads. Because bid-ask spreads widen with volatility, this count measure mechanically provides a partial control for time-varying volatility. The corresponding jump sum measure is a weighted count of the number of events in which the minutely return exceeds $1,5,10$, and 25 half-spreads, with concomitant weights of $1,5,10$, and 25 .

I use relatively simple measures of realized tail events for two reasons. First, large price movements generate picking-off opportunities regardless of the underlying volatility environment so long as they move the "fundamental value" outside of the spread within a very short time period. The model does not distinguish between rare, truly discontinuous price movements and extremely rapid

\footnotetext{
${ }^{14}$ I consider two alternative measures of continuous variation in the Internet Appendix. Coefficient estimates on $\xi_{M K T}$ are robust to the way $C V$ is constructed.
} 
continuous ones associated with high local volatility. ${ }^{15}$ Both harm liquidity providers as other market participants pick off stale quotes. Second, extreme market movements are quite rare, and including moderately large market movements dramatically increases the number of non-zero observations for the dependent variable. The weighted count measures in particular strike a compromise between including moderately extreme events and upweighting truly extreme factor realizations.

I run the regression of Equation (12) for two horizons. First, I run the contemporaneous regression with $\Delta=0$. This regression should have high explanatory power if the model is true because market makers adjust their spreads nearly every instant to reflect anticipated risks. In this specification, the recovered tail risk measure $\xi_{t, M K T}$ has the interpretation of the within-hour average anticipated jump risk. Second, I implement a true forecasting regression with $\Delta=1$. This specification tests whether the lagged tail risk measure predicts future tail realizations over the next hour. Recognizing that jump intensities and volatility are persistent, I add lagged tail realizations and explanatory variables in both specifications. These additions challenge the tail risk measure because the sizable persistence in volatility and jump risks is differenced out. Throughout I drop observations with lags using information from the last hour of the preceding trading day, though results are robust to this choice.

\section{Regression Results}

The top panel of Table II presents results from the baseline test of contemporaneous forecast jump tails on realized jumps. I normalize $\xi_{M K T}$ and VPIN by dividing by their standard deviations to facilitate interpretation of coefficients (for comparison, the standard deviation of the VIX in this period is $9.90 \%$ ). For all tail realization measures, an elevated market tail measure coincides with an increase in the number of realized jumps within the hour, and the coefficients are statistically significant and economically large. ${ }^{16}$ For example, a one standard deviation increase in the market jump tail risk is associated with 4.00 additional realized basis-point jumps per trading hour and 63.7

\footnotetext{
${ }^{15}$ Large basis point and spread movements typically include the infrequent jumps captured by formal jump detection techniques (e.g., Lee and Mykland (2008) and Bollerslev et al. (2013)), but they also include more frequent mediumscale price movements that may not register as jumps in high volatility environments.

${ }^{16}$ Standard errors are robust to heteroskedasticity (both panels) and serial correlation of up to 126 trading hours. Adding hour-year fixed effects has minimal impact on point estimates or their statistical significance. Results are also not driven by extreme observations by recomputing both tables with log counts and log sums.
} 
additional weighted jumps (the measure captures both intensity and size). The jump tail measure is only partly subsumed by the VIX, and they have roughly equal impact on the dependent variable for a one standard deviation change. The coefficient on continuous variation is inconsistent or driven out by the jump tail risk measure; by contrast, the jump tail estimates perform well in explaining the residual variation in realized jumps, which supports its interpretation as a measure of extreme event risk rather than of contemporaneous or anticipated volatility. In most specifications, including volume-bar VPIN attenuates the explanatory power of $\xi_{M K T}$ only slightly, although both variables explain substantial variation in realized jumps. The bottom panel of Table II presents analogous results for forecasting using lagged tail risk measures. All specifications indicate comparably strong predictability of market jump realizations for the hour ahead.

These tests confirm the suggestive evidence of Figures II, III, and IV. The market tail risk measure is associated with both low- and high-frequency realized jump risks. It contains some of the same information as the forward-looking VIX, but its dynamics are intermediate between those of the VIX and of near-term realized volatility. Importantly, the tail risk measure is not spanned by measures of continuous variation, and in fact it drives out these measures for realized spread jumps. These features accord with the design of the measure as a tool for assessing instantaneous extreme event risks. In addition, the tail risk measure forecasts well near-term market jump events.

The spread-implied tail risk measure substantially boosts predictive power over lagged tail realizations and other covariates. Lags alone deliver a period-ahead forecast $R^{2}$ of $61.2 \%$ because tail risk is highly persistent. $\xi_{M K T}$ explains more than $30 \%$ of the remaining variation to increase $R^{2}$ to $73.1 \%$. By contrast, VIX alone increments $R^{2}$ only to $69.3 \%$ of variation in realized basis-point jumps. To provide a back-of-the-envelope estimate of the economic importance of the increase in explanatory power from using my measure, suppose that jumps are independent with average size 15 basis points and that an investor constructs $\xi_{M K T}$ in real time. With an average of 2.95 basis point jumps per hour and approximately 1,630 trading hours per year, annualized "medium-scale" jump variation is $7.8 \%$. An investor equipped to avoid an additional $11.9 \%$ of this variation reduces total exposure to market risk by $0.93 \%$, and using the VIX as a benchmark predictor, adding my measure allows the investor to avoid an additional $6.9 \%$ of this variation and reduce market risk by 
0.54\%. Relative to total annualized daily SPY volatility of $19.0 \%$ during this period, these values represent moderate $4.9 \%$ and $2.8 \%$ reductions in exposure to market volatility, respectively.

\section{B. Other Sources of the Spread}

\section{Inventory Risk}

Risk-averse market makers must be compensated for exposure to price variation of assets in inventory. If market makers do not hedge inventory risks, e.g., using liquid factor-mimicking indexes, market-maker inventories may contaminate tail risks recovered from bid-ask spreads. To address potential contamination by inventory risk, I isolate the component of spreads contributed by adverse selection risks - including picking-off risk - rather than by inventory risks.

I follow Glosten (1987) and decompose the effective (bid-ask) spread into "adverse selection" and "realized spread" components. The adverse selection component captures losses to the market maker when she sells (buys) at $t$ and the price subsequently increases (decreases), and the realized spread component captures the difference between the total spread collected-including compensation for inventory risk - and this permanent price impact. Glosten (1987)'s now-standard proxy for the adverse selection component of spreads is given by the scaled change in midpoint prices between time $t$ and $t+5$ minutes,

$$
h_{i t}^{*}=q_{i t}\left(\frac{m_{i, t+5 m}-m_{i t}}{m_{i t}}\right) \text {, }
$$

where $m_{i t}$ is the prevailing quote midpoint in security $i$ at time $t, q_{i t}=+1$ for market-maker sells, and $q_{i t}=-1$ for market-maker buys. Buys and sells are determined by the Lee and Ready (1991) algorithm. I average this adverse selection value by stock and minute to obtain a continuous proxy for adverse selection costs, and I substitute $h^{*}$ for effective half spreads in constructing a modified liquidity composite, $V h^{*} / d$.

Table III replicates Table II using the modified liquidity composite as the dependent variable. All coefficients retain comparable levels of economic and statistical significance, but point estimates are typically smaller using the adverse selection component of the spread. The difference in coefficients is telling about the sources of market maker risks. First, the similarity of results with and without 
compensation for inventory risks in the liquidity composite indicates that the tail risk measure is not materially undermined by variation in inventory risk throughout the sample. As Figure V suggests, the first-order impact of using the modified liquidity composite is a simple rescaling of recovered market tail risks, and the correlation between the modified and unmodified tail risk series is $92 \%$. Second, the smaller coefficients obtained by using $h^{*}$ rather than $h$ indicate that liquidity providers require greater compensation for their services when market jump risk is high. This finding accords with higher inventory risk or tighter intermediary capital constraints in bad times. The increased power of the VIX, continuous variation, and VPIN for explaining realized jumps suggests that much of the time-variation in realized spreads is spanned by volatility measures also associated with jump realizations.

\section{Non-Jump Adverse Selection}

Adverse selection imposes costs on market makers through two qualitatively different modes:

1. Intermediation against informed traders with long-lived information (slow);

2. Picking off by stale-quote snipers (fast).

Cross-sectional variation in spreads reflects differences in exposures to long-lived informational risk in addition to picking-off risk. Economically, estimation bias arises when factor exposures align with the risk imposed by long-lived informed traders. For example, for market tail estimates to be biased, assets with high market betas must be more exposed to non-jump adverse selection risk. Formally, slow adverse selection biases tail risk estimates if the volume- and depth-scaled component of halfspreads not associated with tail risk exposures is cross-sectionally correlated with factor loadings.

Such alignment is tantamount to market participants having private information on the underlying factor. Gorton and Pennacchi (1993) and others suggest that private informational advantages are unlikely for systematic factors. Gorton and Pennacchi (1993) argue that composite products, and by extension, corresponding factors that are mimicked, are exposed to minimal risk of nonpublic adverse selection because insider information is typically known at the security level rather than at the aggregate level. 
I support this argument by showing that controlling for stock-level slow adverse selection does not meaningfully affect recovered tail risks for the market factor. Specifically, I include the probability of informed trading (PIN) measure of Easley and O'Hara (1992) and Easley, Kiefer, O'Hara and Paperman (1996) to control for the arrival rate of informed traders. The PIN measure is constructed under the assumption that order flow tilts in the direction of information that persists throughout the trading day unbeknownst to the market maker. Such information is long-lived with respect to the horizon of HFT market makers, and as such, PIN should primarily encapsulate costs of slow rather than fast adverse selection. I compute stock-level PIN estimates quarterly for the 2005-2013 sample period using the methodology of Yan and Zhang (2014). ${ }^{17}$

Table IV reports the results of the contemporaneous regression of realized jumps on implied market tail risk, where the implied tail risk estimation equation adds the stock-date PIN characteristic to the right-hand side of Equation (11). Like the tail risk measure net of potential inventory risk, the tail risk measure net of slow adverse selection risk performs similarly to the baseline specification in matching time variation in market tail realizations. Indeed, no tail risk coefficient in Table IV is statistically distinguishable at the $5 \%$ level from its counterpart in Table II, and the time series correlation of baseline and PIN-adjusted series is 98.7\%. Omitted stock-level "slow" adverse selection does not bias my measure because it exhibits low correlation with factor betas, notwithstanding its strong relation to the adverse selection component of the spread.

\section{Applications}

\section{A. The 2010 Flash Crash}

In a spectacular market episode, the May 6, 2010 Flash Crash saw equity indices decline by 5-6\% and revert almost completely within a 30-minute period. Assessing welfare consequences associated with the 2010 Flash Crash has proved even more challenging than explaining the event's causes. ${ }^{18}$ Kirilenko, Kyle, Mehrdad and Tuzun (2011) tabulate buyers and sellers in S\&P 500 E-

\footnotetext{
${ }^{17}$ An active literature describes issues encountered in estimating PIN in fast-moving equity markets. Results are robust across alternate PIN estimation methodologies.

${ }^{18}$ Explanations for the Flash Crash abound. Among these are that a single large trader's faulty algorithm caused a severe order flow imbalance (CFTC and SEC (2010)); extreme order flow toxicity drove away market makers and collapsed liquidity (Easley, López de Prado and O'Hara (2012)); and a breakdown in cross-market arbitrage brought
} 
mini futures ("E-mini") during the Flash Crash, but no corresponding data exists to evaluate the extensive knock-on redistributive effects associated with extreme turnover in equities and index products. Moreover, much popular discussion following the 2010 Flash Crash centers on distrust of the market mechanism and fears of future crashes, yet fears of future crashes are inherently difficult to quantify.

My measure of instantaneous jump risks is well-suited to evaluating the costs of rapid jump events. I require only that such events exceed the market makers' typical holding period and thus contribute to picking-off risk. Market makers fear picking off on both the initial price decline (or rise) and on the return because extended price disruptions of several minutes affect a security's "terminal value" with respect to the market maker's trading horizon. ${ }^{19}$

To demonstrate its utility in assessing the costs of flash crashes, I construct tail risk measures around and during May 6, 2010 using the one-factor market model. A one-factor market model is particularly apt in this instance because the 2010 Flash Crash originated in S\&P 500 E-mini futures, a key price discovery market for the S\&P 500. I estimate tail risks every 15 minutes to achieve high resolution on the crash interval (2:30-3:00pm) and surrounding trading hours.

Figure VI plots market and idiosyncratic tail measures from 12:45pm on May 5, 2010 through 12:45pm on May 7, 2010 for each quarter hour from 9:45am to 3:45pm. To capture innovations and place risk changes in context of normal intraday and slow-moving macroeconomic variation, I difference the value at the same quarter hour on May 4, 2010, and divide by the standard deviation of differences for the same quarter hour over the preceding 63 trading days up to and including May 4, 2010 (a calendar quarter). Several new features are readily apparent. First, the Flash Crash itself is associated with extreme contemporaneous elevations of both the market (99 standard deviations) and idiosyncratic (91 standard deviations) tail risk measures. Second, jump risks remain elevated for the remainder of the trading day and throughout May 7, 2010, even after the initial shock subsides. Third, market tail risks increase a quarter hour before idiosyncratic tail risks, likely because the Flash Crash begins in the E-mini, a nearly ideal S\&P 500 index proxy. Volume-adjusted spreads

about an extreme price of immediacy (Menkveld and Yueshen (2015)).

${ }^{19}$ Kirilenko et al. (2011) find support for market makers not holding through "long" crashes. Rather than maintaining inventory during the 2010 Flash Crash, high-frequency market makers engaged in extreme turnover, or "hot potato" activity. 
widen and depth falls (1) simultaneously across many stocks and (2) proportionally to market betas rather than in equal measure across stocks.

Intriguingly, the market tail risk measure increases by 20 standard deviations in the $2: 15-2: 30 \mathrm{pm}$ interval relative to its value on May 4, 2010. Market makers anticipate distress conditions even before Waddell \& Reed initialized its trading algorithm at 2:32pm (Menkveld and Yueshen (2015)). ${ }^{20}$ All told, the preceding relations align with several existing explanations of the Flash Crash and reassure that the proposed risk measure effectively anticipates near-term tail risks.

By contrast with my measure, options data used for constructing the VIX and other forwardlooking risk measures incorporate volatility and jump information days or weeks beyond the duration of fleeting, mean-reverting flash crashes, and correspondingly are much less affected by such events. Although the VIX is somewhat elevated during the Flash Crash, the Flash Crash is not an extreme event for the VIX except in the rapidity of its increase intraday. An equally large and comparably sharp increase in implied volatility occurs in the same month: the normalized change-in-VIX measure achieves the same level on May 20, a day coinciding with a local maximum for the VIX (Figure VII). Likewise, my measure differs from VPIN in achieving an all-time high before the Flash Crash occurs and having no false positives for sufficiently high levels of implied market risk (Andersen and Bondarenko (2014a,b, 2015)).

The spread-implied measure also provides a longer-term view of changes in tail risk around the 2010 Flash Crash. The tail risk measure should remain elevated if the 2010 Flash Crash truly increases stability fears among market participants. Evidence for this effect is unambiguously negative. From Figure VII, we observe that both tail risk measures return to roughly their pre-Flash Crash levels only days later, and indeed tail risk in the week after the Flash Crash is statistically indistinguishable from tail risk in the week before it. Although longer-term average tail risks (and spreads) increase slightly in post-Crash weeks, these increases occur after May 10, 2010, several days after the crash. Subsequent tail risk elevations are inconsistent with a story of heightened perceived Flash Crash risk and likely arise from macroeconomic sources. In light of these results, it is difficult

\footnotetext{
${ }^{20}$ Moreover, as detailed in the Internet Appendix, market buy depth systematically declines relative to market sell depth in line with market betas, suggesting that liquidity providers are especially concerned about the risk of market down jumps prior to the Flash Crash. The joint CFTC and SEC report on the 2010 Flash Crash documents a similar, lopsided deterioration of market depth for the E-Mini in the hour preceding the Flash Crash.
} 
to argue that the 2010 Flash Crash had a persistent effect on market fears: high-frequency market makers should be among the most attuned to potential flash crash risk, yet their pricing of crash risks in spreads quickly reverts.

\section{B. Federal Open Market Committee Announcements}

The Federal Open Market Committee (FOMC) holds eight scheduled meetings per year to discuss salient economic and financial issues and policy responses. At the conclusion of each meeting, the FOMC releases a statement summarizing its views and actions. The release of these statements - typically scheduled to within minutes - is among the most important scheduled macroeco-

nomic news announcements. Several recent papers have documented empirical regularities associated with these announcements. Savor and Wilson (2013) and Lucca and Moench (2015) find that announcement-day average stock returns comprise a large fraction of the annual equity premium, and Savor and Wilson (2014) find that the CAPM works well for cross-sectional pricing during FOMC days.

Rational explanations for these phenomena require that risk be highly time-varying as measured in FOMC event time. Although realized market volatility is lower than average during the FOMC pre-announcement period, elevated and difficult-to-observe jump risk may offer a partial, rational explanation. High market jump risk requires a higher equity premium, and the increased importance of market jump risk can enforce the CAPM if the CAPM works for discontinuous returns (as suggested by Bollerslev, Li and Todorov (2016)). Moreover, the sample of FOMC announcements may be too short for these jump risks to have been realized.

I apply my tail risk extraction methodology to analyze jump risks around FOMC announcements and find evidence against this hypothesis of elevated market tail risk during the high-return period. For each quarter-hour interval and calendar year, I compute the average FOMC announcement date tail risk, subtract the average non-FOMC announcement tail risk, and normalize by dividing by the respective standard deviation of tail risks across all days for each quarter hour and year. I use fullperiod average spreads to measure jump risks because announcements are typically centered on the start of the quarter hour, so the previous quarter hour's measure is a better assessment of anticipated 
risks. Importantly, the scheduling of announcements historically has not been precise enough to violate the assumption of Poisson arrivals of fundamental news: although market participants know the planned FOMC announcement time, there is significant uncertainty about precisely when the news comes out. This uncertainty is on the order of several minutes, as Figure VIII illustrates, and translates in the context of the model into a sharply elevated jump risk for the interval containing the announcement.

Figure VIII plots deviations in perceived tail risks around FOMC announcements. For every year in the sample, FOMC announcements indeed coincide with sharply elevated perceived tail risk relative to the non-FOMC dates in the same year. ${ }^{21}$ Relative to the preceding quarter hour, most years also see a marked, anticipatory increase in implied tails in the quarter hour before the FOMC announcement (typically 2:00-2:14pm). ${ }^{22}$ These anticipatory movements in tail risk can be explained by (1) uncertainty in the exact timing of the information release, as suggested by within-year dispersion of the announcement minute around the year's modal quarter hour, and (2) fear of early information leakage and attendant price jumps, as suggested by the empirical investigations of Bernile, Hu and Tang (2015) and Kurov, Sancetta, Strasser and Wolfe (2015). Notably the measure does not simply reflect contemporaneous realized volatility around the FOMC announcement: Lucca and Moench (2015) instead find that volatility is monotone decreasing in the hours prior to the FOMC announcement (Figure 3 of their work).

Although the tail risk measure registers increased risk in the quarter hours around FOMC news, implied tail risk is typically lower than average prior to the FOMC announcement, in parallel with the period's reduced volatility. There is little evidence that the high average returns the morning of FOMC announcements can be attributed to market jump fears. The pre-FOMC announcement drift and announcement-day success of the CAPM therefore cannot be attributed to an increase in the (physical) probability or magnitude of market jumps.

\footnotetext{
${ }^{21}$ Crisis years have a much larger unnormalized FOMC announcement effect, particularly in 2008. However, the large fluctuations in tail risk during 2008-2009 counterbalance the increased differences between FOMC and nonFOMC day means.

${ }^{22}$ These early-response results accord with the findings of Jiang, Lo and Verdelhan (2011) in the U.S. Treasury bond market. The authors find increased spreads, decreased depth, and stagnant trading volume in the five minutes before major market news announcements.
} 


\section{The 2007-2008 Financial Crisis}

I study the 2007-2008 Financial Crisis to demonstrate the potential of my approach to identify factor- or sector-specific extreme event risks. Specifically, I apply the jump extraction technique to discern the magnitude of perceived jump risks to a "financials" factor independent from market risks. The choice of the financial sector is driven by its economic importance during the 2000 s as well as the difficulty of disentangling financial sector risks from market risks using alternate methods; during this period, the daily correlation of XLF, my financial sector factor-mimicking portfolio, and the SPY often exceeds 90\%. At the same time, Aït-Sahalia and Xiu (2015) demonstrate that the first two principal components of high-frequency returns correspond well with market and financial sector innovations, respectively, suggesting that innovations in these factor risks should be detectable at high frequency.

The central regression in this analysis modifies Equation (11) to accommodate a financials factor: $:^{23}$

$$
\left(\frac{V h}{d}\right)_{i t}=\tilde{\xi}_{t}+\xi_{t, M K T} \beta_{i, M K T}+\xi_{t, F I N}\left|\beta_{i, F I N}\right|+\epsilon_{i t}, \forall t
$$

I exclude co-jump terms for the market and financial factors because (1) the joint risk of tail events in the market and financial factors is not of independent interest and (2) rank tests around market jumps find evidence against factor co-jumps with the aggregate market (Li, Lin, Tauchen and Todorov (2016)). Appendix B discusses this point in additional detail.

Figure IX plots the time series of implied financial sector tail risks. The recovered series of financial tail risks is visually similar to the one-factor market risks of Figure III, but it differs somewhat in the events corresponding with the largest changes in financial sector risks. Several events associated with large market risk increases in the one-factor model are in fact specific to the financial sector. Large-scale asset purchases, bank bailout legislation, and bank nationalization news feature prominently for financials, but not for the aggregate market in the two-factor model.

\footnotetext{
${ }^{23}$ The market factor model is readily estimated in part because reliable negative betas are quite rare among common stocks. Consequently, excluding stocks with betas below a small, positive threshold excludes few stocks so little data is lost. However, imposing this non-negativity restriction with other candidate asset pricing factors is undesirable, as $\beta$ s need not be centered around one, and they are frequently negative for several common factors. Appendix B shows that taking absolute values correctly accounts for negative betas with respect to non-market factors such as XLF.
} 
Conversely, the FOMC interest rate target announcements of 2007-2008 and the S\&P U.S. credit rating downgrade shock the aggregate market but not the financial sector separately.

I now test formally whether the recovered financials tail risks indeed correspond with jumps in the financials factor. By analogy with Table II, Table V compares medium-scale tail realizations in the XLF to $\xi_{F I N}$ in the two-factor model of Equation (14). As before, I split specifications based on (1) the number of minutely differences of more than 10 basis points ("jump count") and the weighted sum of jumps of 5, 10,25, and 100 basis points and (2) the number of minutely differences of more than 5 half-spreads ("jump count") and the weighted sum of jumps of 1, 5, 10, and 25 half-spreads. Rather than using the VIX, I include market jump tails as a control to quantify the degree to which jump types are successfully disentangled.

All specifications feature a strong relation between financial sector tail risk and realized financial sector jumps. A one standard deviation increase in $\xi_{F I N}$ corresponds with approximately 5.1 more basis-point jumps and 2.0 spread jumps on a baseline standard deviation of 10.7 and 2.5 XLF jumps per hour, respectively. In bivariate regressions, including market tail risks further increases explanatory ability. Reassuringly, financial sector tail risk has a greater association with XLF jump realizations than does market tail risk.

The strong relation between market tail risk and XLF jump realizations comes about because SPY and XLF frequently cojump during the financial crisis - as Figure IX indicates, several "market" news items also contribute to sharp movements in the financial sector. To evaluate whether $\xi_{F I N}$ picks up financial sector events that are not also aggregate market events, I add contemporaneous SPY jump counts and jump sums as an additional control. $\xi_{F I N}$ remains significantly associated with XLF jumps net of market cojumps, whereas $\xi_{M K T}$ is driven out. This brief analysis suggests that the jump tail extraction technique successfully and separately identifies market and financial sector risks at high frequency.

\section{Conclusion}

High-frequency market makers continually extract signals from order flow to optimize their provision of liquidity. Intermediaries must pay special attention to signals on potential discontinuous 
price movements, because such movements can generate losses from "picking off" by other fast traders. Securities with larger factor loadings are more exposed to discontinuous factor movements than are securities with smaller loadings. As a consequence, liquidity prices are higher for these securities, and the cross section of liquidity costs embeds significant information about near-term return factor risks. The key contribution of this paper is the development of a methodology for extracting some of this factor risk information in real time.

Bid-ask spreads are unique among existing data sources in their ability to reveal intraday changes in extreme event risk for common factors in stock returns. This paper thus takes a first step toward bringing microstructure data to bear on measurement challenges in related fields. My methodology is distinguished from existing methods in its ability to obtain information about (1) a wide array of return factor risks (2) at an intraday frequency (3) for short look-ahead horizons.

This cross-sectional approach offers a valuable tool for researchers to evaluate extreme event risks. High-frequency tail risk estimates provides a viable alternative to the VIX and other leading indicators of market turmoil. Regulators, too, might benefit: the extreme rise in tail risk before the onset of the 2010 Flash Crash suggests that the measure may have predictive power for severe market disruptions.

By contrast with options-implied measures, my measure cannot anticipate tail realizations beyond a short forecasting horizon, nor does it provide direct information on the persistence or serial correlation of jump events. For these reasons, my measure is best interpreted as market expectations of tail realizations over short horizons, and its use restricted to intraday tail risk assessment or retrospective analysis of crash fears and determinants thereof.

Notwithstanding market makers' limited planning horizon, empirical linkages between nearterm factor risks and disasters of the Rietz (1988) and Barro (2006) variety are surprisingly strong. Seminal events of the Great Recession and 2007-2008 Financial Crisis manifest as large changes in implied tail risks in the immediate term, and recent work by Andersen, Fusari and Todorov (2015) suggests that market crashes have their origins in sequences of "small" jumps captured by my methodology. Further study of these linkages is left for future investigation. 


\section{References}

Aït-Sahalia, Yacine and Dacheng Xiu, "Principal Component Analysis of High Frequency Data," NBER Working Paper September 2015.

Andersen, Torben G. and Oleg Bondarenko, "Reflecting on the \{VPIN $\}$ Dispute," Journal of Financial Markets, 2014, 17, 53 - 64.

_ and _ , "VPIN and the Flash Crash," Journal of Financial Markets, 2014, 17, 1 - 46.

_ and _, "Assessing Measures of Order Flow Toxicity and Early Warning Signals for Market Turbulence," Review of Finance, 2015, 19 (1), 1-54.

_ and Tim Bollerslev, "Intraday Periodicity and Volatility Persistence in Financial Markets," Journal of Empirical Finance, 1997, 4 (2-3), 115-158.

_ , Nicola Fusari, and Viktor Todorov, "The Risk Premia Embedded in Index Options," Journal of Financial Economics, 2015.

Backus, David, Mikhail Chernov, and Ian Martin, "Disasters Implied by Equity Index Options," The Journal of Finance, 2011, 66 (6), 1969-2012.

Bakshi, Gurdip, Nikunj Kapadia, and Dilip Madan, "Stock Return Characteristics, Skew Laws, and the Differential Pricing of Individual Equity Options," Review of Financial Studies, 2003, $16(1), 101-143$.

Barndorff-Nielsen, O. E., P. Reinhard Hansen, A. Lunde, and N. Shephard, "Realized Kernels in Practice: Trades and Quotes," Econometrics Journal, 2009, 12 (3), C1-C32.

Barro, Robert J., "Rare Disasters and Asset Markets in the Twentieth Century," The Quarterly Journal of Economics, 2006, 121 (3), 823-866.

Bernile, Gennaro, Jianfeng Hu, and Yuehua Tang, "Can Information Be Locked-Up? Informed Trading Ahead of Macro-News Announcements," Working Paper 2015. 
Bollerslev, Tim and Viktor Todorov, "Estimation of Jump Tails," Econometrica, 2011, 79 (6), $1727-1783$.

_ and _ "Tails, Fears, and Risk Premia," The Journal of Finance, 2011, 66 (6), 2165-2211.

_ and _ "Time-Varying Jump Tails," Journal of Econometrics, 2014, 183 (2), 168-180. Analysis of Financial Data.

_, George Tauchen, and Hao Zhou, "Expected Stock Returns and Variance Risk Premia," Review of Financial Studies, 2009, 22 (11), 4463-4492.

_ , Sophia Zhengzi Li, and Viktor Todorov, "Roughing up Beta: Continuous vs. Discontinuous Betas, and the Cross-Section of Expected Stock Returns," Journal of Financial Economics, 2016, $120(3), 464-490$.

_, Viktor Todorov, and (Sophia) Zhengzi Li, "Jump Tails, Extreme Dependencies, and the Distribution of Stock Returns," Journal of Econometrics, 2013, 172 (2), 307-324.

Brownlees, C.T. and G.M. Gallo, "Financial Econometric Analysis at Ultra-High Frequency: Data Handling Concerns," Computational Statistics $\& 3$ Data Analysis, 2006, 51 (4), 2232-2245.

Brunnermeier, Markus K. and Lasse Heje Pedersen, "Market Liquidity and Funding Liquidity," Review of Financial Studies, 2009, 22 (6), 2201-2238.

Budish, Eric, Peter Cramton, and John Shim, "The High-Frequency Trading Arms Race: Frequent Batch Auctions as a Market Design Response," Quarterly Journal of Economics, November 2015, 130 (4), 1547-1621.

Cardella, Laura, Jia Hao, and Ivalina Kalcheva, "Make and Take Fees in the U.S. Equity Market," Working Paper 2015.

Carr, Peter and Liuren Wu, "What Type of Process Underlies Options? A Simple Robust Test," The Journal of Finance, 2003, 58 (6), 2581-2610.

CFTC and SEC, "Findings Regarding the Market Events of May 6, 2010," Report of the Staffs of the CFTC and SEC to the Joint Advisory Committee on Emerging Regulatory Issues 2010. 
Chordia, Tarun, Richard Roll, and Avanidhar Subrahmanyam, "Commonality in Liquidity," Journal of Financial Economics, 2000, 56 (1), 3-28.

Christie, William G. and Paul H. Schultz, "Why do NASDAQ Market Makers Avoid OddEighth Quotes?," The Journal of Finance, 1994, 49 (5), 1813-1840.

Comerton-Forde, Carole, Terrence Hendershott, Charles M. Jones, Pamela C. Moulton, and Mark S. Seasholes, "Time Variation in Liquidity: The Role of Market-Maker Inventories and Revenues," The Journal of Finance, 2010, 65 (1), 295-331.

Copeland, Thomas E. and Dan Galai, "Information Effects on the Bid-Ask Spread," The Journal of Finance, 1983, 38 (5), 1457-1469.

Cremers, K. J. Martijn and Jianping Mei, "Turning over Turnover," Review of Financial Studies, 2007, 20 (6), 1749-1782.

Easley, David and Maureen O'Hara, "Time and the Process of Security Price Adjustment," The Journal of Finance, 1992, 47 (2), 577-605.

_, Marcos Lopez de Prado, and Maureen O'Hara, "Discerning Information from Trade Data," Journal of Financial Economics, 2016, 120 (2), 269 - 285.

_, Marcos M. López de Prado, and Maureen O'Hara, "Flow Toxicity and Liquidity in a High-frequency World," Review of Financial Studies, 2012, 25 (5), 1457-1493.

_, Nicholas M. Kiefer, Maureen O'Hara, and Joseph B. Paperman, "Liquidity, Information, and Infrequently Traded Stocks," The Journal of Finance, 1996, 51 (4), 1405-1436.

Fama, Eugene F. and James D. MacBeth, "Risk, Return, and Equilibrium: Empirical Tests," Journal of Political Economy, 1973, 81 (3), 607-636.

Fleming, Michael J. and Monika Piazzesi, "Monetary Policy Tick-by-Tick," Working Paper 2005.

Foucault, Thierry, Ailsa Röell, and Patrik Sandås, "Market Making with Costly Monitoring: An Analysis of the SOES Controversy," Review of Financial Studies, 2003, 16 (2), 345-384. 
_, Ohad Kadan, and Eugene Kandel, "Liquidity Cycles and Make/Take Fees in Electronic Markets," The Journal of Finance, 2013, 68 (1), 299-341.

_, Sophie Moinas, and Erik Theissen, "Does Anonymity Matter in Electronic Limit Order Markets?," Review of Financial Studies, 2007, 20 (5), 1707-1747.

Glosten, Lawrence R., "Components of the Bid-Ask Spread and the Statistical Properties of Transaction Prices," The Journal of Finance, 1987, 42 (5), 1293-1307.

Gorton, Gary B. and George G. Pennacchi, "Security Baskets and Index-Linked Securities," The Journal of Business, 1993, 66 (1), 1-27.

Han, Jungsuk, Mariana Khapko, and Albert S Kyle, "Liquidity with High-Frequency Market Making," Swedish House of Finance Research Paper, 2014, (14-06).

Harris, Jeffrey H. and Paul H. Schultz, "The Importance of Firm Quotes and Rapid Executions: Evidence from the January 1994 SOES Rules Changes," Journal of Financial Economics, 1997, $45(1), 135-166$.

Hasbrouck, Joel and Duane J. Seppi, "Common Factors in Prices, Order Flows, and Liquidity," Journal of Financial Economics, 2001, 59 (3), 383 - 411.

Hendershott, Terrence, Charles M. Jones, and Albert J. Menkveld, "Does Algorithmic Trading Improve Liquidity?," Journal of Finance, February 2011, 66 (1), 1-33.

Herskovic, Bernard, Bryan Kelly, Hanno Lustig, and Stijn Van Nieuwerburgh, "The Common Factor in Idiosyncratic Volatility: Quantitative Asset Pricing Implications," Journal of Financial Economics, 2016, 119 (2), 249 - 283.

Holden, Craig W. and Stacey Jacobsen, "Liquidity Measurement Problems in Fast, Competitive Markets: Expensive and Cheap Solutions," The Journal of Finance, 2014, 69 (4), 1747-1785.

Huang, Xin and George Tauchen, "The Relative Contribution of Jumps to Total Price Variance," Journal of Financial Econometrics, 2005, 3 (4), 456-499. 
Jiang, George J., Ingrid Lo, and Adrien Verdelhan, "Information Shocks, Liquidity Shocks, Jumps, and Price Discovery: Evidence from the U.S. Treasury Market," Journal of Financial and Quantitative Analysis, 4 2011, 46, 527-551.

Kelly, Bryan and Hao Jiang, "Tail Risk and Asset Prices," Review of Financial Studies, 2014, $27(10), 2841-2871$.

Kirilenko, Andrei, Albert S. Kyle, Samadi Mehrdad, and Tugkan Tuzun, "The Flash Crash: The Impact of High Frequency Trading on an Electronic Market," Working Paper May 2011.

Koenker, Roger and Jose A. F. Machado, "Goodness of Fit and Related Inference Processes for Quantile Regression," Journal of the American Statistical Association, 1999, 94 (448), 1296-1310.

Korajczyk, Robert A. and Ronnie Sadka, "Pricing the Commonality Across Alternative Measures of Liquidity," Journal of Financial Economics, 2008, 87 (1), 45 - 72.

Kurov, Alexander, Alessio Sancetta, Georg Strasser, and Marketa Halova Wolfe, "Price Drift Before U.S. Macroeconomic News," Working Paper 2015.

Lee, Charles M. C. and Mark J. Ready, "Inferring Trade Direction from Intraday Data," The Journal of Finance, 1991, 46 (2), 733-746.

Lee, Suzanne S. and Per A. Mykland, "Jumps in Financial Markets: A New Nonparametric Test and Jump Dynamics," Review of Financial Studies, 2008, 21 (6), 2535-2563.

Li, Jia, Huidi Lin, George Tauchen, and Viktor Todorov, "Rank Tests at Jump Events," Working Paper 2016.

_, Viktor Todorov, and George Tauchen, "Jump Regressions," Working Paper 2014.

Lo, Andrew W. and Jiang Wang, "Trading Volume: Definitions, Data Analysis, and Implications of Portfolio Theory," Review of Financial Studies, 2000, 13 (2), 257-300.

Lucca, David O. and Emanuel Moench, "The Pre-FOMC Announcement Drift," The Journal of Finance, 2015, 70 (1), 329-371. 
Mancini, Cecilia, "Non-Parametric Threshold Estimation for Models with Stochastic Diffusion Coefficient and Jumps," Scandinavian Journal of Statistics, 2009, 36 (2), 270-296.

Menkveld, Albert J. and Bart Zhou Yueshen, "The Flash Crash: A Cautionary Tale about Highly Fragmented Markets," Working Paper 2015.

Nagel, Stefan, "Evaporating Liquidity," Review of Financial Studies, 2012, 25 (7), 2005-2039.

Rietz, Thomas A., "The Equity Risk Premium: A Solution," Journal of Monetary Economics, 1988, $22(1), 117-131$.

Savor, Pavel and Mungo Wilson, "How Much Do Investors Care About Macroeconomic Risk? Evidence from Scheduled Economic Announcements," Journal of Financial and Quantitative Analysis, 2013, 48 (4), 343-375.

_ and _ , "Asset Pricing: A Tale of Two Days," Journal of Financial Economics, 2014, 113 (2), $171-201$.

Shanken, Jay, "On the Estimation of Beta-Pricing Models," Review of Financial Studies, 1992, 5 (1), 1-33.

Todorov, Viktor and Tim Bollerslev, "Jumps and Betas: A New Framework for Disentangling and Estimating Systematic Risks," Journal of Econometrics, 2010, 157 (2), 220 - 235.

Yan, Yuxing and Shaojun Zhang, "Quality of PIN Estimates and the PIN-Return Relationship," Journal of Banking \&6 Finance, 2014, 43 (0), 137 - 149.

Yueshen, Bart Zhou, "Queuing Uncertainty in Limit Order Market," Working Paper 2014. 


\section{Figure I: Potential Intermediation Outcomes}

This figure presents potential outcomes of offering liquidity with a half-spread $h$. Values at terminal nodes represent market-maker payoffs, and branch labels represent conditional probabilities. The green line indicates liquidity supply to a fundamental trader, whereas the red line indicates picking off by other potential market makers.

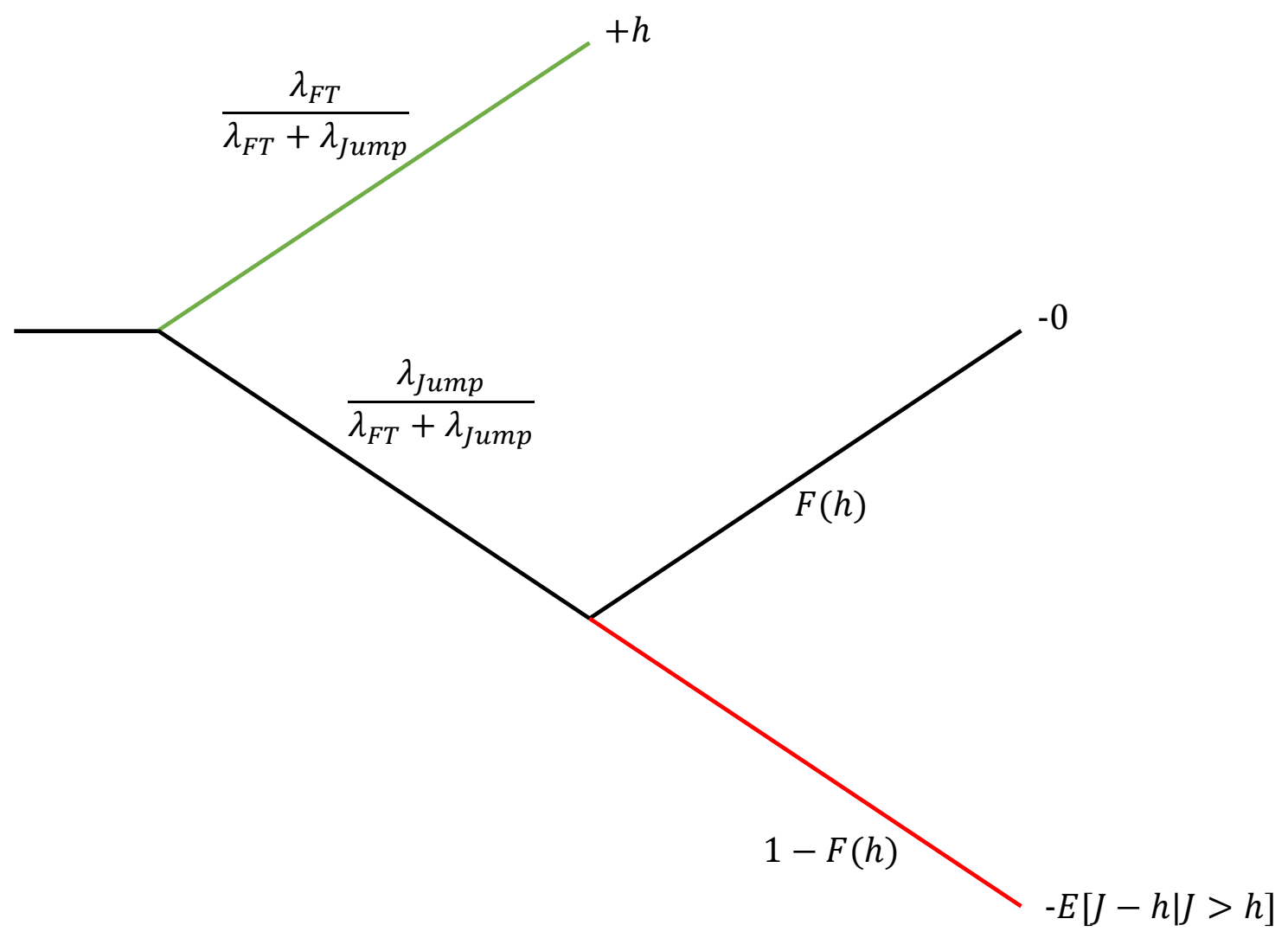


Figure II: Hourly Market Tail Risks, 2004-2013

This figure plots rolling one-month means of hourly cross-sectional slope estimates $\xi_{m t}$ (blue) for Equation (11) for each trading date in 2004-2013. Dashed blue bands depict the corresponding $95 \%$ confidence intervals estimated by pairs bootstrap. Realized volatility (red) is estimated using minutely squared returns on the SPY and scaled to the hourly frequency. The VIX is plotted using the right axis (gold) for comparison. NBER recession dates are marked in gray.

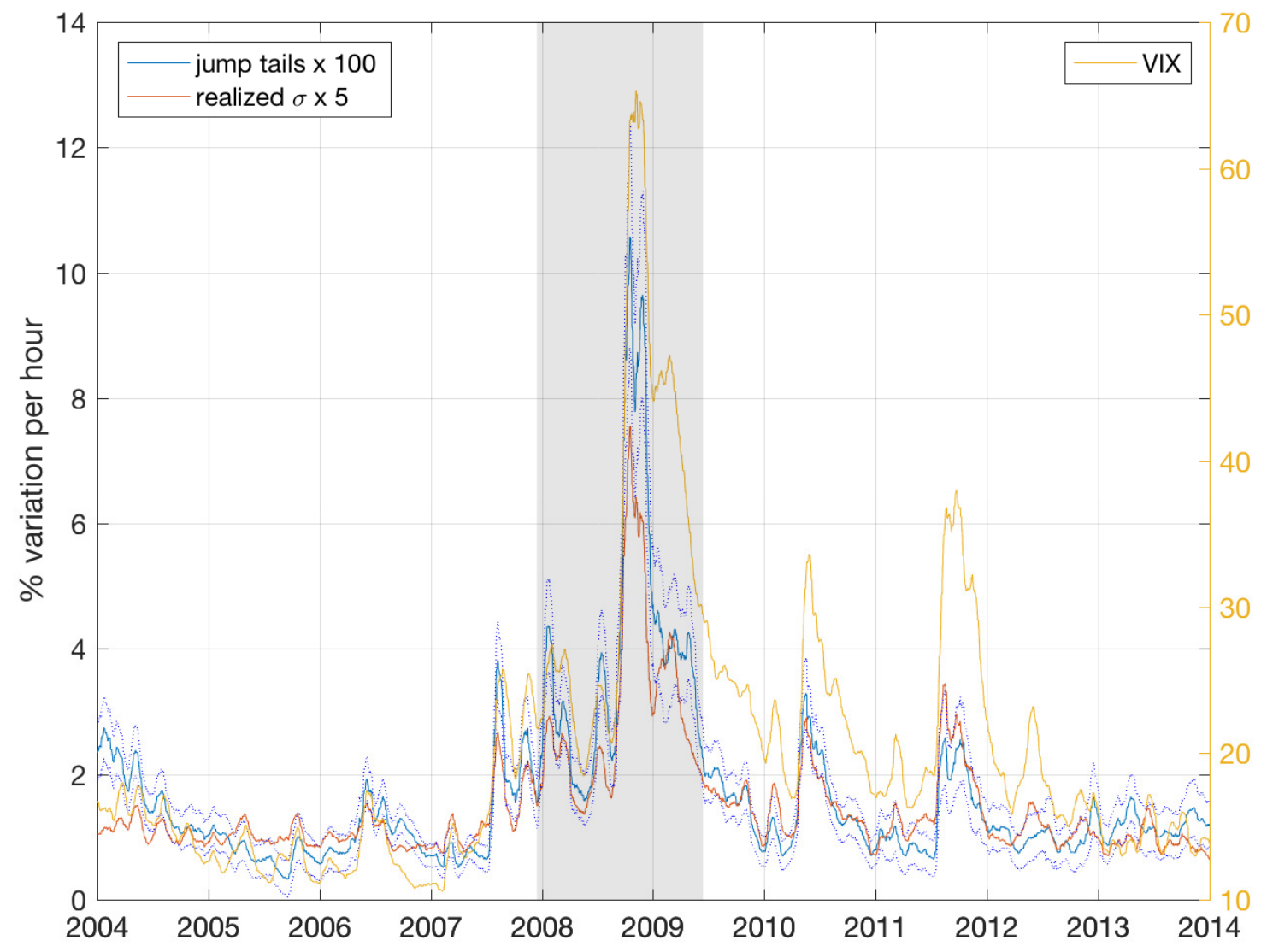


Figure III: Anticipated Jumps by Hour, 2004-2013

This figure plots hourly estimated market tail risks in a one-factor market model. The fifteen largest increases in tail risks within a one-month window are overlaid with a green $\mathrm{X}$. Changes are measured as the tail risk at date $t$ and hour $h$ less the tail risk at date $t-1$ and hour $h$. The table below offers a brief description of coincident events of tail risk news days. Standardized values divide by the full time-series standard deviation. Blue events coincide with the most extreme increases in the VIX within 24 hours. Implied market tails on October 10, 2008 are truncated for visual clarity.

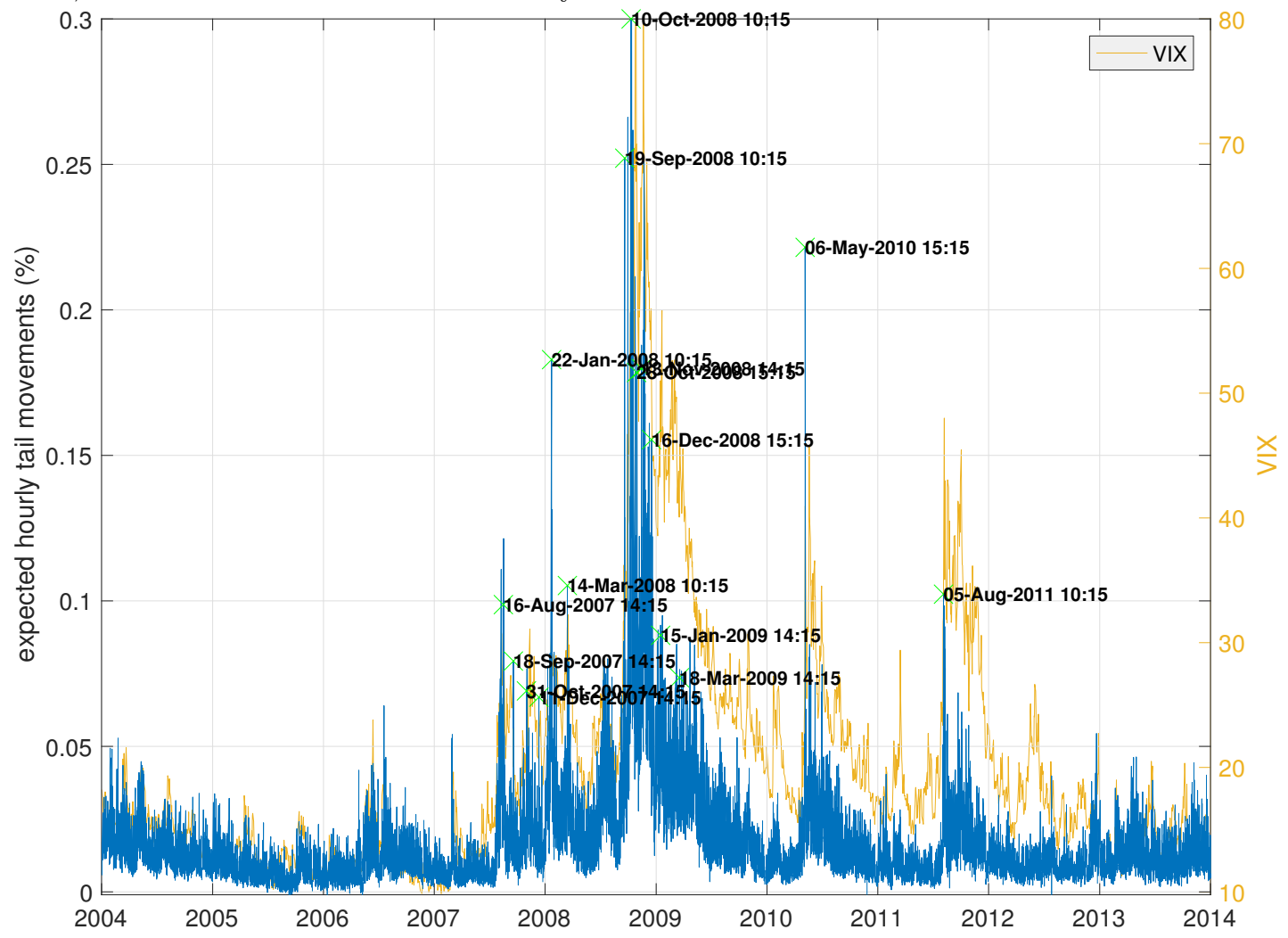

\begin{tabular}{lcl}
\hline Hour & Std. Value & Event \\
\hline 16-Aug-07 14:15 & 6.54 & Fed approves changes to its primary credit discount window facility \\
18-Sep-07 14:15 & 6.08 & FOMC lowers Fed funds target 50 basis points to $4.75 \%$ \\
31-Oct-07 14:15 & 5.29 & FOMC lowers Fed funds target 25 basis points to $4.5 \%$ \\
11-Dec-07 14:15 & 4.84 & FOMC lowers Fed funds target 25 basis points to $4.25 \%$ \\
22-Jan-08 10:15 & 9.71 & FOMC lowers Fed funds target 75 basis points to $3.5 \%$ \\
14-Mar-08 10:15 & 5.88 & New York Fed drops bailout deal to save Bear Stearns \\
19-Sep-08 15:15 & 13.27 & TARP proposed; short-selling ban; global campaign by central banks \\
10-Oct-08 15:15 & 23.71 & Stock market crashes in Asia, Europe, and the United States \\
28-Oct-08 15:15 & 9.95 & First round of TARP bank bailouts $(\$ 115$ billion) \\
13-Nov-08 14:15 & 11.31 & Large negative jobless claims surprise; most new claims since $9 / 11$ \\
16-Dec-08 15:15 & 7.65 & FOMC lowers Fed funds target to 0-0.25\% \\
15-Jan-09 14:15 & 4.93 & Senate approves release of $\$ 350$ billion of TARP funds \\
18-Mar-09 14:15 & 4.04 & FOMC announces $\$ 1$ trillion in new Treasury bond and MBS purchases \\
06-May-10 15:15 & 16.83 & 2010 Flash Crash \\
05-Aug-11 14:15 & 4.68 & S\&P downgrades U.S. government debt to AA + \\
\hline
\end{tabular}


Figure IV: Intraday Jumps by Hour, 2005-2013

This figure plots hourly means of market tail risks by hour and year (top) and of weighted realized basis point jumps by hour and year (bottom). Realized basis point jumps are a weighted sum of the number of events in which the minutely return exceeds $5,10,25$, and 100 basis points, with respective weights of 5,10 , 25 , and 100. The underlying economic model is a one-factor market model. 2008 is a positive outlier and is omitted from both diagrams to preserve resolution on the other years in the sample.

(a) Anticipated Jump Risks (ex 2008)

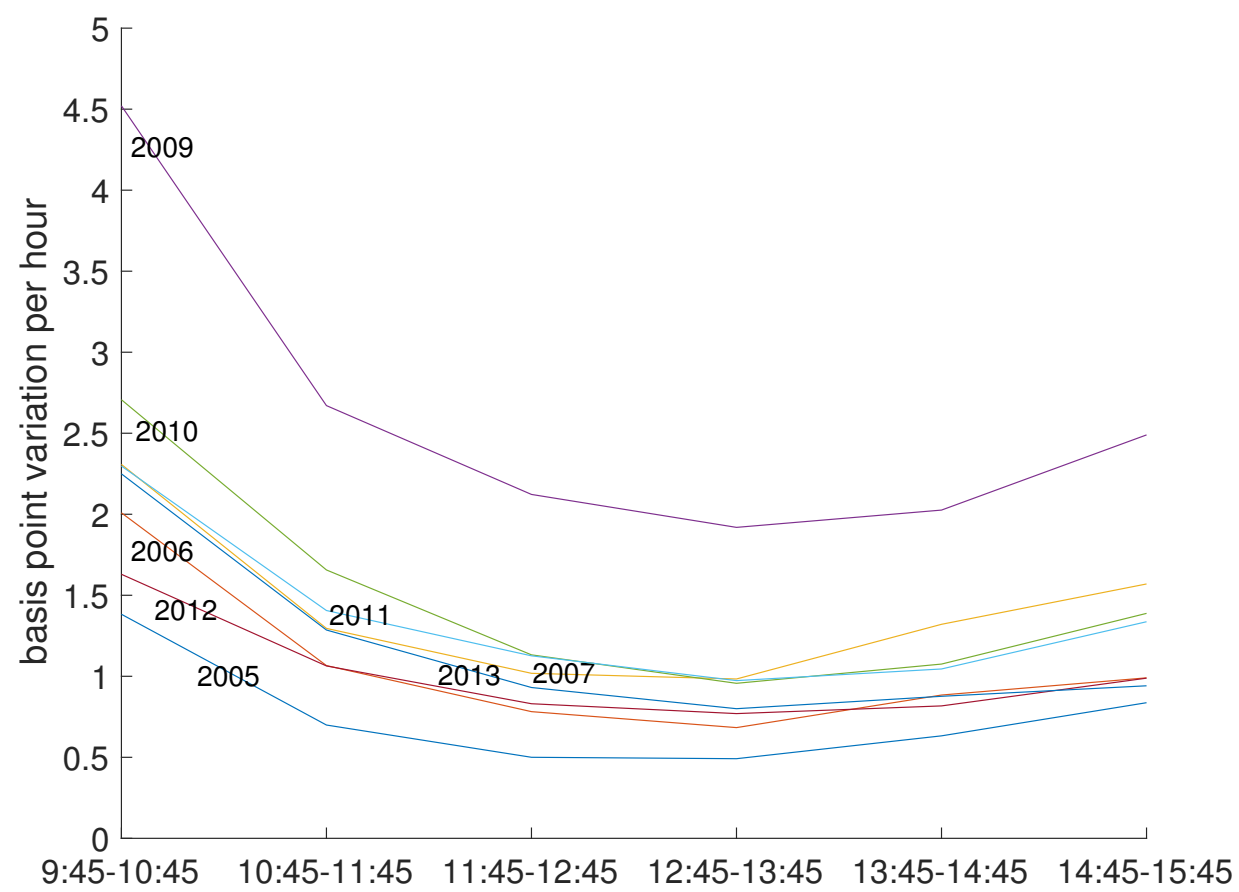

(b) Realized Basis Point Jumps (ex 2008)




Figure V: Comparison of Implied Market Jump Risks Net of Alternative Sources of the Spread

Figures plot rolling ten-day means of hourly estimated market tail risks for each trading date in 2004-2013. The blue line is the baseline estimation of Equation (11). The red line replaces the effective half-spread with realized adverse selection. The gold line adds a stock-quarter control for the probability of informed trading. The bottom plot aligns the series by subtracting series means and dividing by series standard deviations.

(a) Forecast Market Tail Risks

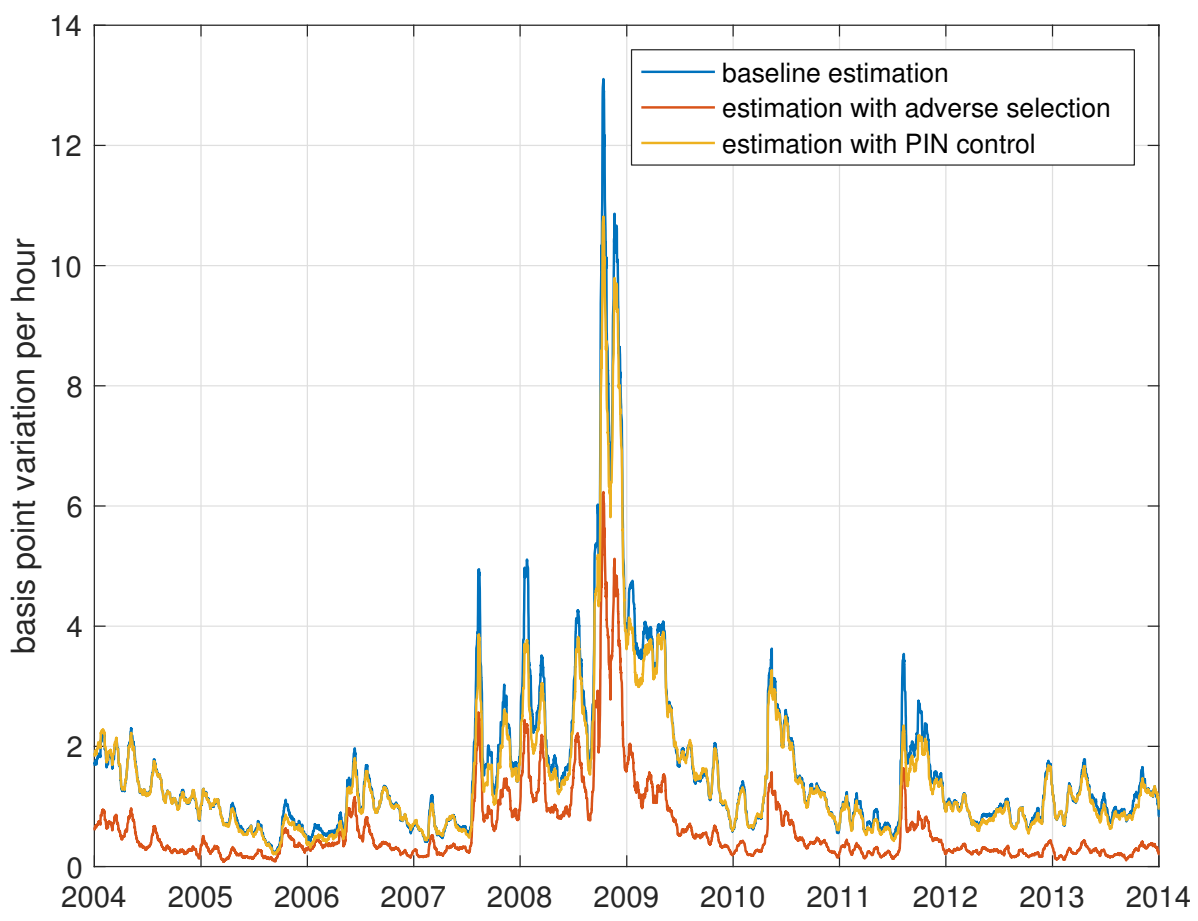

(b) Forecast Market Tail Risks (Normalized)

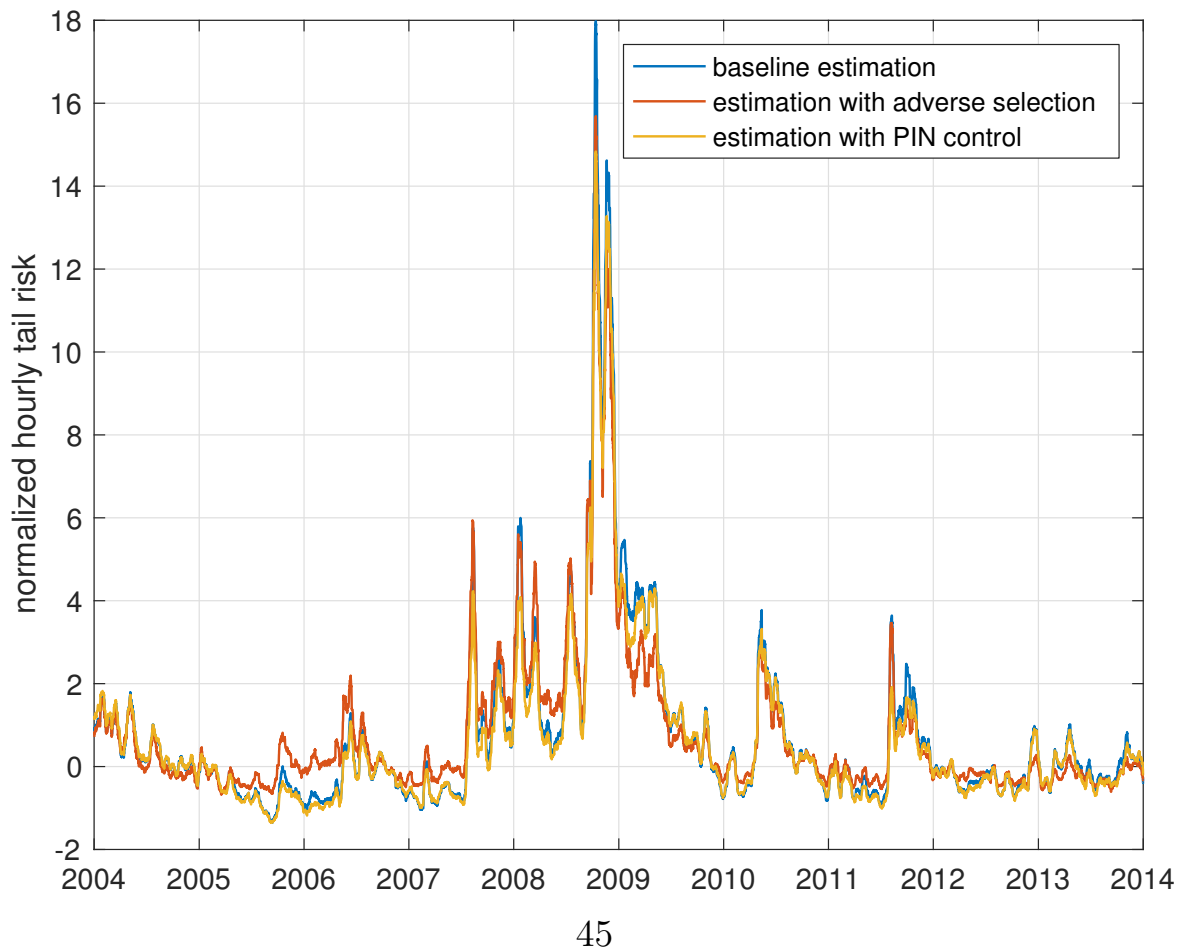


Figure VI: Standardized Deviations in Jump Expectations around the 2010 Flash Crash

This figure plots standardized deviations in jump expectations around the May 6, 2010 Flash Crash. Tail risks are assessed with a market model with 15-minute increments. For each quarter hour, I normalize each value by subtracting the value during the same quarter hour on May 4, 2010, and dividing by the 15-minute specific standard deviation of this value across all dates in the 63 trading days up to and including May 4 , 2010. The top figure plots the normalized value for the market factor before (green), during (red), and after (orange) May 6, 2010. The dotted line plots the normalized 15-minute estimate for realized volatility. Black circles denote the 2:30-3:00pm interval during which the crash and reversion occur. The middle and bottom plots provide the corresponding information for the idiosyncratic jump factor and the VIX.

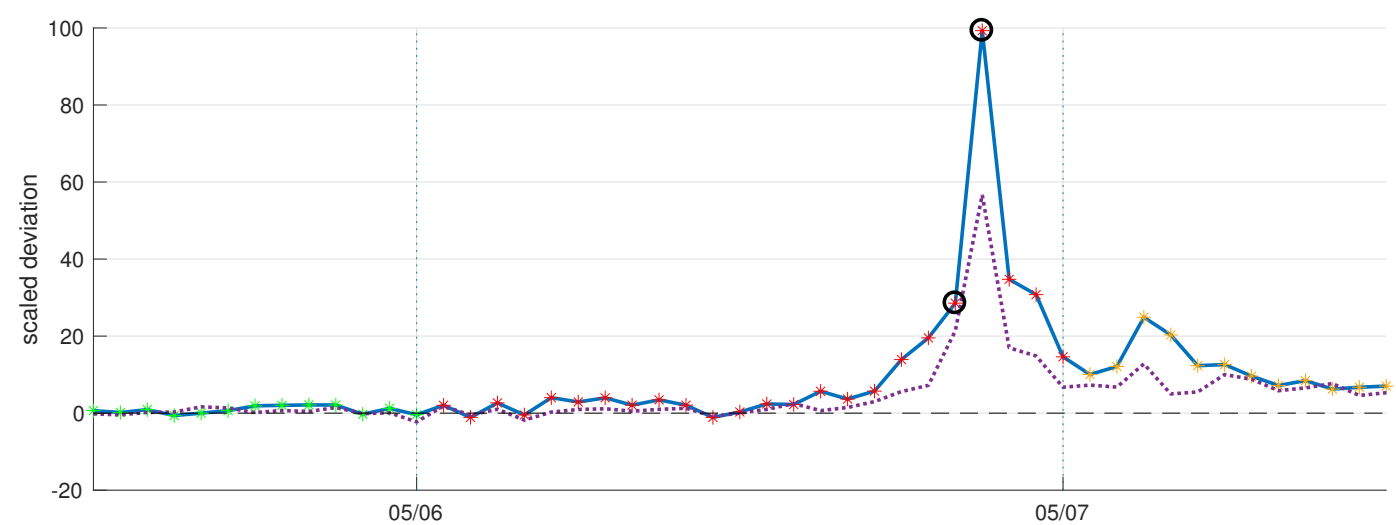

(a) Anticipated Market Factor Jumps

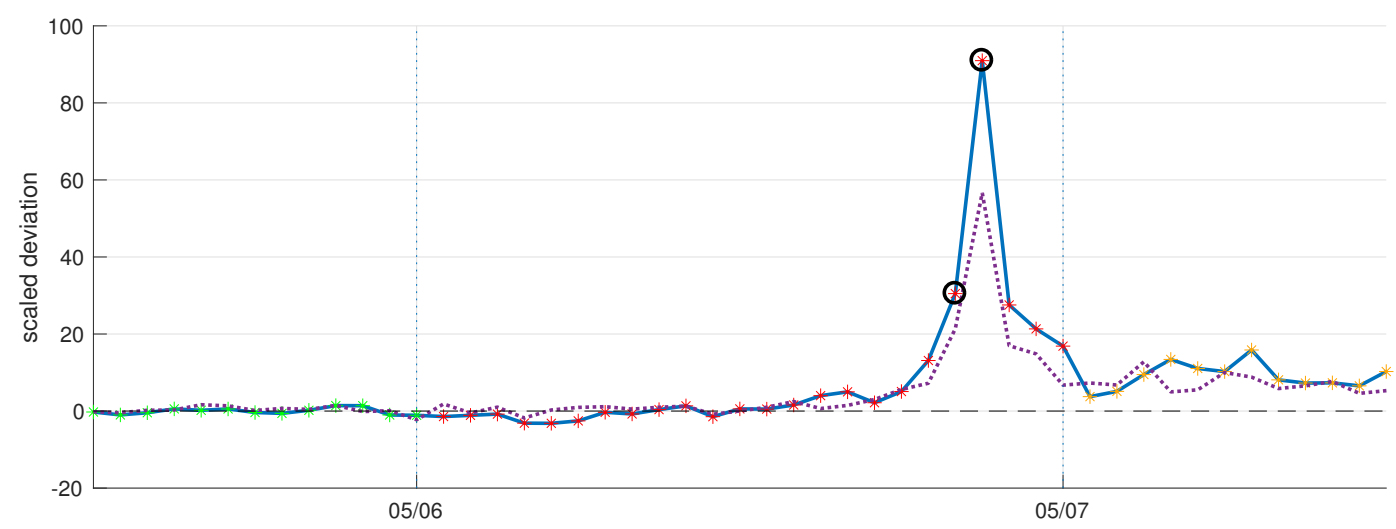

(b) Anticipated Idiosyncratic Jumps

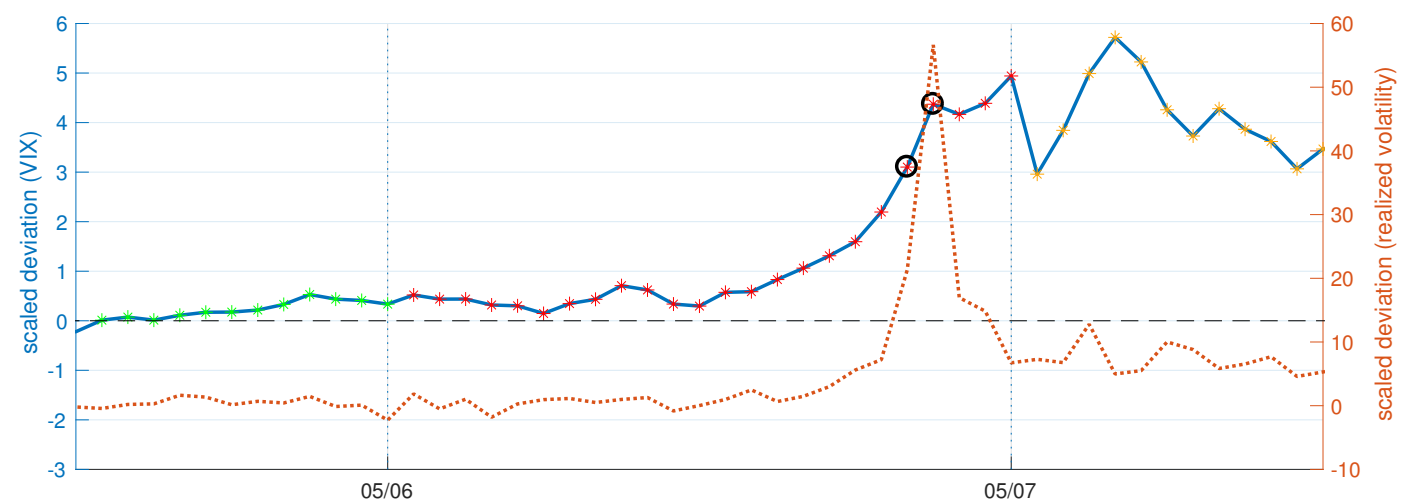

(c) Intraday VIX 
Figure VII: Long-Term Effects of the 2010 Flash Crash on Implied Jump Risk

This figure plots five-day backward-looking moving averages of the quarter-hour jump measure around the 2010 Flash Crash. Blue and red lines correspond to implied market and idiosyncratic jumps, with their associated scale on the left axis. The orange line corresponds with the VIX, with its associated scale on the right axis. The dashed line marks May 6, 2010, and the dotted line marks two business days after the event, May 10, 2010.

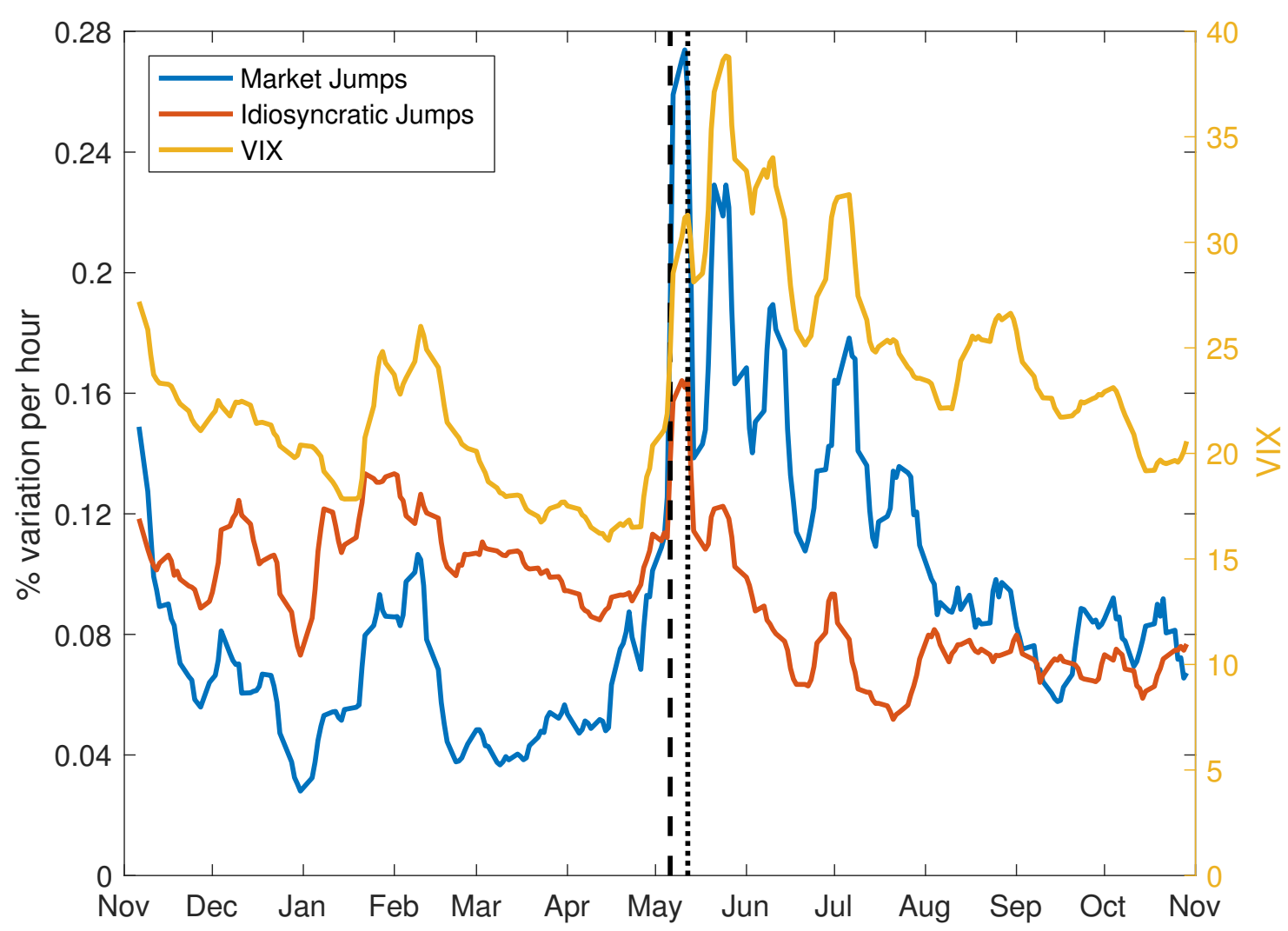


Figure VIII: Intraday Tail Risks around FOMC Announcements

This figure plots intraday tail risks for the market factor for FOMC and non-FOMC announcement dates from 2005-2013. For each quarter-hour interval and calendar year, I compute the average FOMC announcement date tail risk and subtract the average non-FOMC announcement tail risk. I then normalize this quantity by the standard deviation of tail risks for all days in the same quarter hour and year. Stars indicate FOMC announcement times retrieved by minute from the first post-statement news article on Bloomberg or Dow Jones newswires following Fleming and Piazzesi (2005). The lower plot zooms in on the 1:45-2:45pm interval.

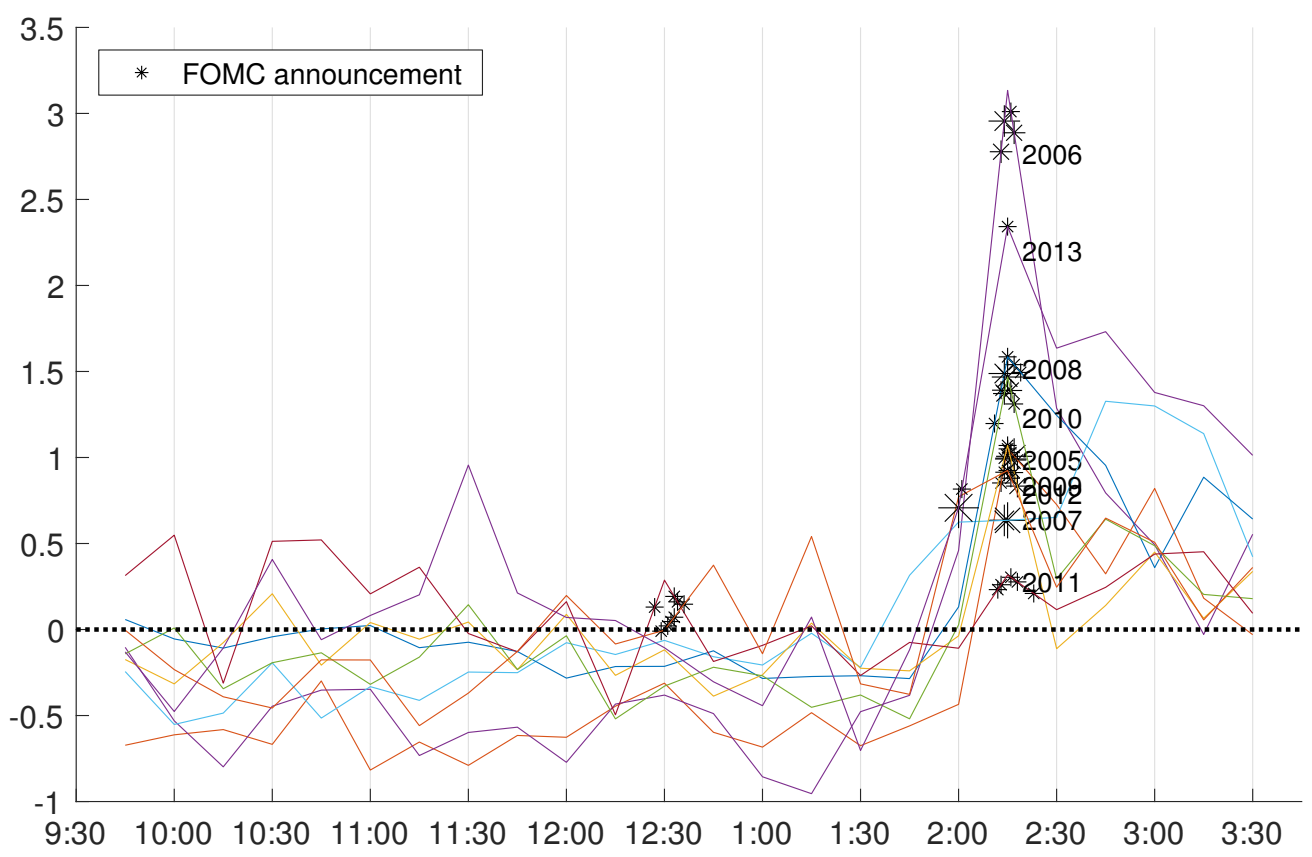

(a) Quarter-Hour Deviations



(b) Quarter-Hour Deviations, 1:45-2:45pm 
Figure IX: Anticipated XLF Jumps by Hour, 2004-2013

This figure plots hourly estimated tail risks for financial and market risks in a two-factor market and financials model. The fifteen largest increases in tail risks within a one-month window are overlaid with a green $\mathrm{X}$. Changes are measured as the tail risk at date $t$ and hour $h$ less the tail risk at date $t-1$ and hour $h$. The table below offers a brief description of coincident events of tail risk news days. Standardized values divide by the full time-series standard deviation. Red events correspond with extreme changes in both factors (using the two-factor model) within 24 hours. Implied tails on October 10, 2008 are truncated for visual clarity.

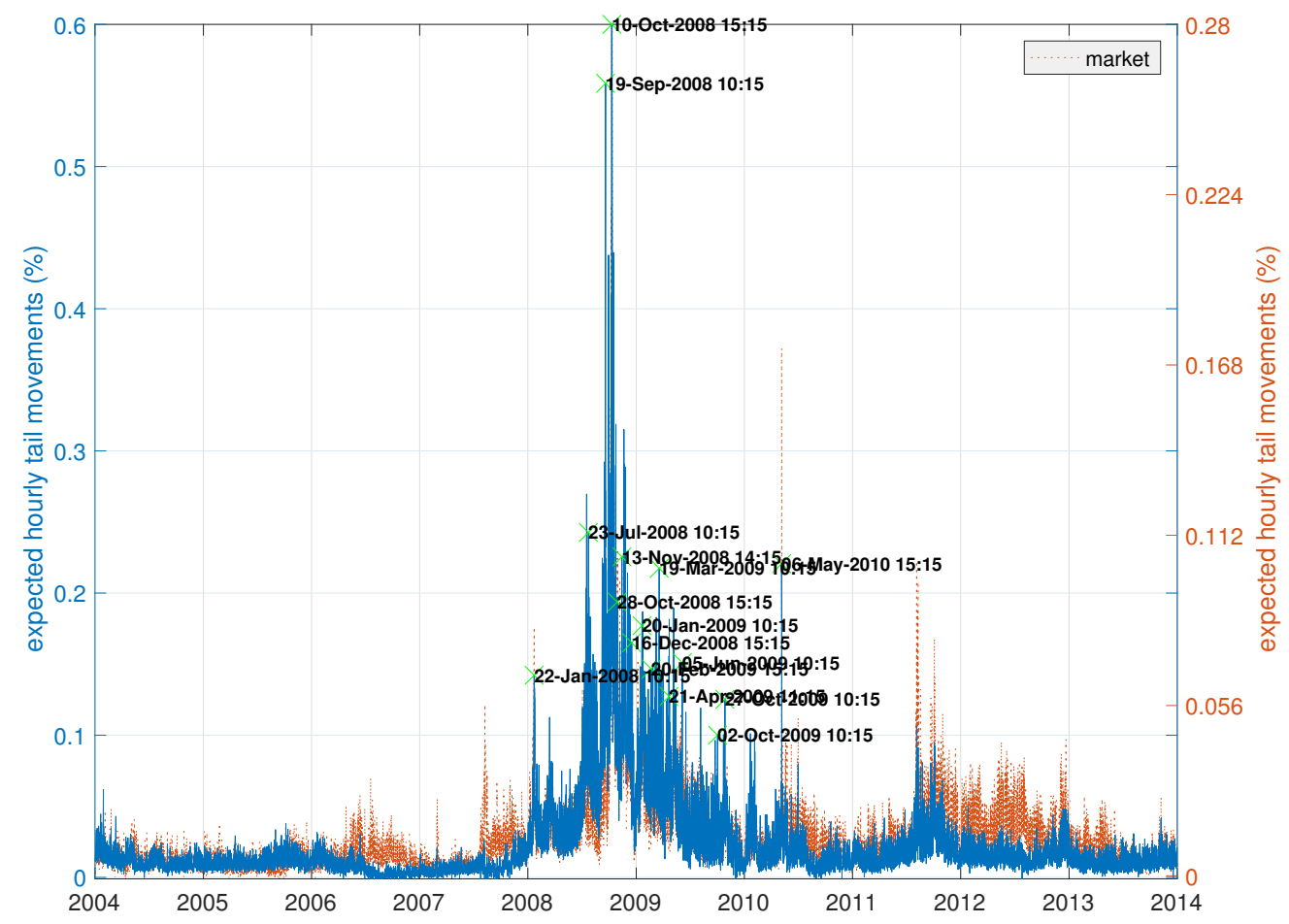

\begin{tabular}{lcl}
\hline Hour & Std. Value & Event \\
\hline 22-Jan-08 10:15 & 5.88 & Worldwide "Black Monday" \\
14-Mar-08 10:15 & 3.48 & New York Fed drops bailout deal to save Bear Stearns \\
23-Jul-08 10:15 & 4.70 & House passes Fannie and Freddie rescue bill after Bush drops opposition \\
19-Sep-08 10:15 & 19.89 & TARP proposed; short-selling ban; global campaign by central banks \\
10-Oct-08 10:15 & 24.13 & Stock market crashes in Asia, Europe, and the United States \\
28-Oct-08 15:15 & 6.53 & First round of TARP bank bailouts ( $\$ 115$ billion) \\
13-Nov-08 14:15 & 9.18 & Large negative jobless claims surprise; most new claims since 9/11 \\
16-Dec-08 15:15 & 4.62 & FOMC lowers Fed funds target to 0-0.25\% \\
20-Jan-09 10:15 & 4.27 & Discussion of bank recapitalization, bank stocks down 20-25\% \\
20-Feb-09 15:15 & 5.98 & Dodd suggests bank nationalization may be necessary \\
19-Mar-09 15:15 & 6.23 & FOMC announces $\$ 1$ trillion in new Treasury bond and MBS purchases \\
21-Apr-09 11:15 & 4.19 & BofA reports sharp rise in bad loans, financial stocks drop more than 10\% \\
05-Jun-09 10:15 & 4.84 & Rumors circulate on FDIC push to gain greater control over Citigroup \\
27-Oct-09 10:15 & 3.92 & House Financial Services Committee presents draft "Too Big to Fail" law \\
06-May-10 15:15 & 11.17 & 2010 Flash Crash \\
\hline
\end{tabular}


Table I: Correlations of Tail Measure with Other Volatility and Tail Measures

This table reports correlations of tail and volatility measures over the 2004-2013 sample period. The spreadimplied measure $\xi_{M K T}$ uses Equation (11) to compute hourly market tail risk estimates. VIX is the (30-day) CBOE Volatility Index. Realized volatility is the square root of the average squared one-minute SPY returns within each hour. Options-implied tails are the weekly parametric left-tail risk estimates from Figure 7 of Bollerslev and Todorov (2014). VPIN uses bulk-volume classification and volume bars (10 buckets) for the front-month E-mini S\&P 500 futures contract. These two series are available through 2011 only. Daily and weekly values are equal-weighted hourly values within the respective time bin.

(a) Weekly Correlations

\begin{tabular}{cccccc}
\hline & $\xi_{M K T}$ & Options-Implied Tail & VIX & Realized Volatility & VPIN \\
\hline \hline$\xi_{M K T}$ & - & 0.77 & 0.85 & 0.93 & 0.81 \\
Options-Implied Tail & 0.77 & - & 0.89 & 0.80 & 0.65 \\
VIX & 0.85 & 0.89 & - & 0.91 & 0.79 \\
Realized Volatility & 0.93 & 0.80 & 0.91 & - & 0.83 \\
VPIN & 0.81 & 0.65 & 0.79 & 0.83 & - \\
\hline
\end{tabular}

(b) Daily Correlations

\begin{tabular}{ccccc}
\hline & $\xi_{M K T}$ & VIX & Realized Volatility & VPIN \\
\hline \hline$\xi_{M K T}$ & - & 0.81 & 0.91 & 0.74 \\
VIX & 0.81 & - & 0.88 & 0.75 \\
Realized Volatility & 0.91 & 0.88 & - & 0.78 \\
VPIN & 0.74 & 0.75 & 0.78 & - \\
\hline
\end{tabular}

(c) Hourly Correlations

\begin{tabular}{ccccc}
\hline & $\xi_{M K T}$ & VIX & Realized Volatility & VPIN \\
\hline \hline$\xi_{M K T}$ & - & 0.71 & 0.87 & 0.65 \\
VIX & 0.71 & - & 0.82 & 0.74 \\
Realized Volatility & 0.87 & 0.82 & - & 0.72 \\
VPIN & 0.65 & 0.74 & 0.72 & - \\
\hline
\end{tabular}




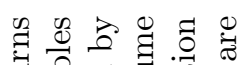
㻤

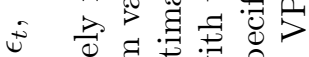

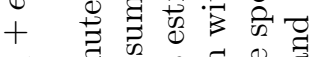

$\triangleleft$ 当

।

$z_{1}^{\infty}$ क

ค

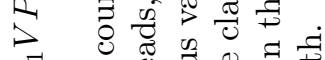

$\because$ ᄀ

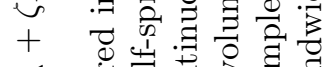

$\checkmark$ )



1

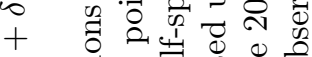

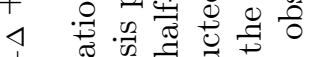

1.

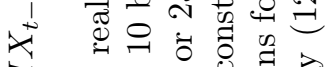

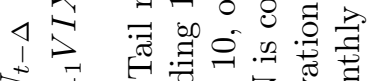

之

¿

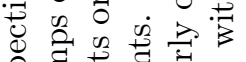



की है

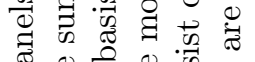

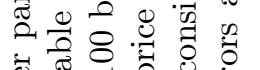

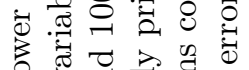

茫

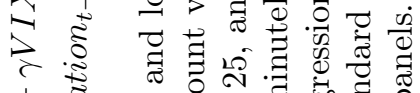

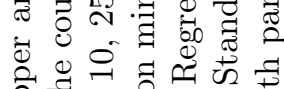

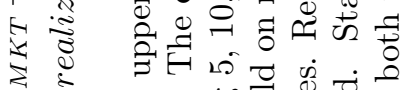

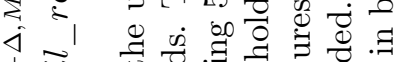

w

+ ।

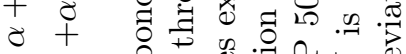

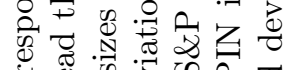

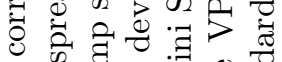

$\neg$ ○一

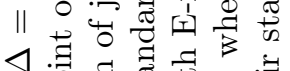

光

ఠ.

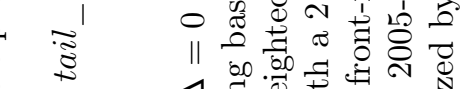

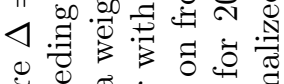

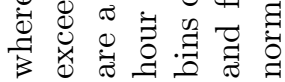

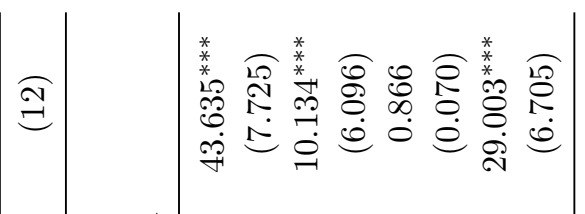



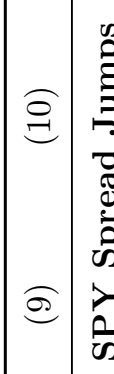

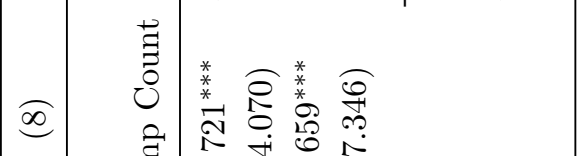

$\overparen{\infty}$

E

.

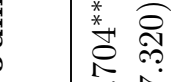

กิ่

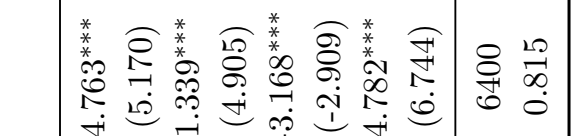



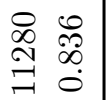

$\infty^{2}$

节

एक

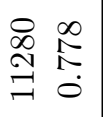

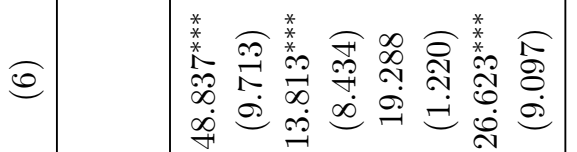

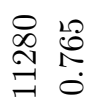

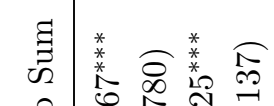

(1)

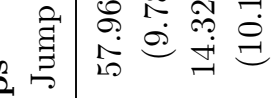

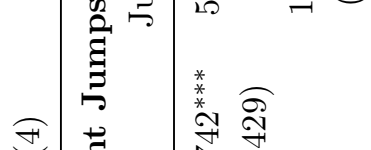

ङ



(2)

ฮิ

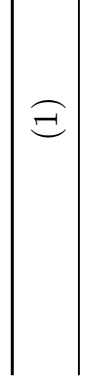

西

通

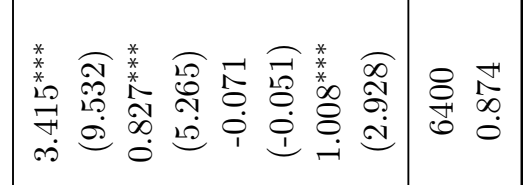

岁

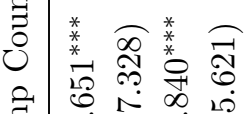

棦

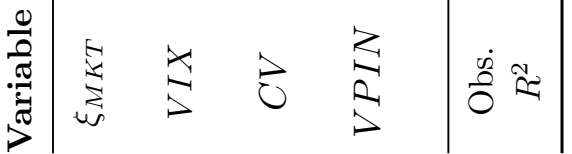

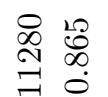

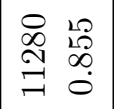

贯
品

.

卷

这

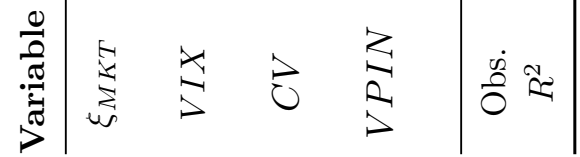

$\begin{array}{ll}0 & \\ 0 & 0 \\ 0 & 0 \\ 0 & 0 \\ 0 & 0\end{array}$

$\begin{array}{ll}0 & \overrightarrow{0} \\ \tilde{8} & \stackrel{0}{0} \\ 0\end{array}$

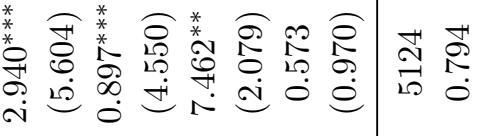

兽

菅
竞

:

\%

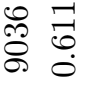

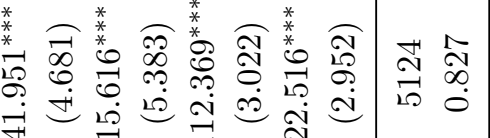

¿̊.

$\mathrm{e}$
2

${ }^{*} 60$

:

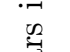

焉

3
0
$b$
0

門

డై

$\Xi$

$\stackrel{5}{5}$

๘ี

.$\stackrel{0}{0}$

蛋 







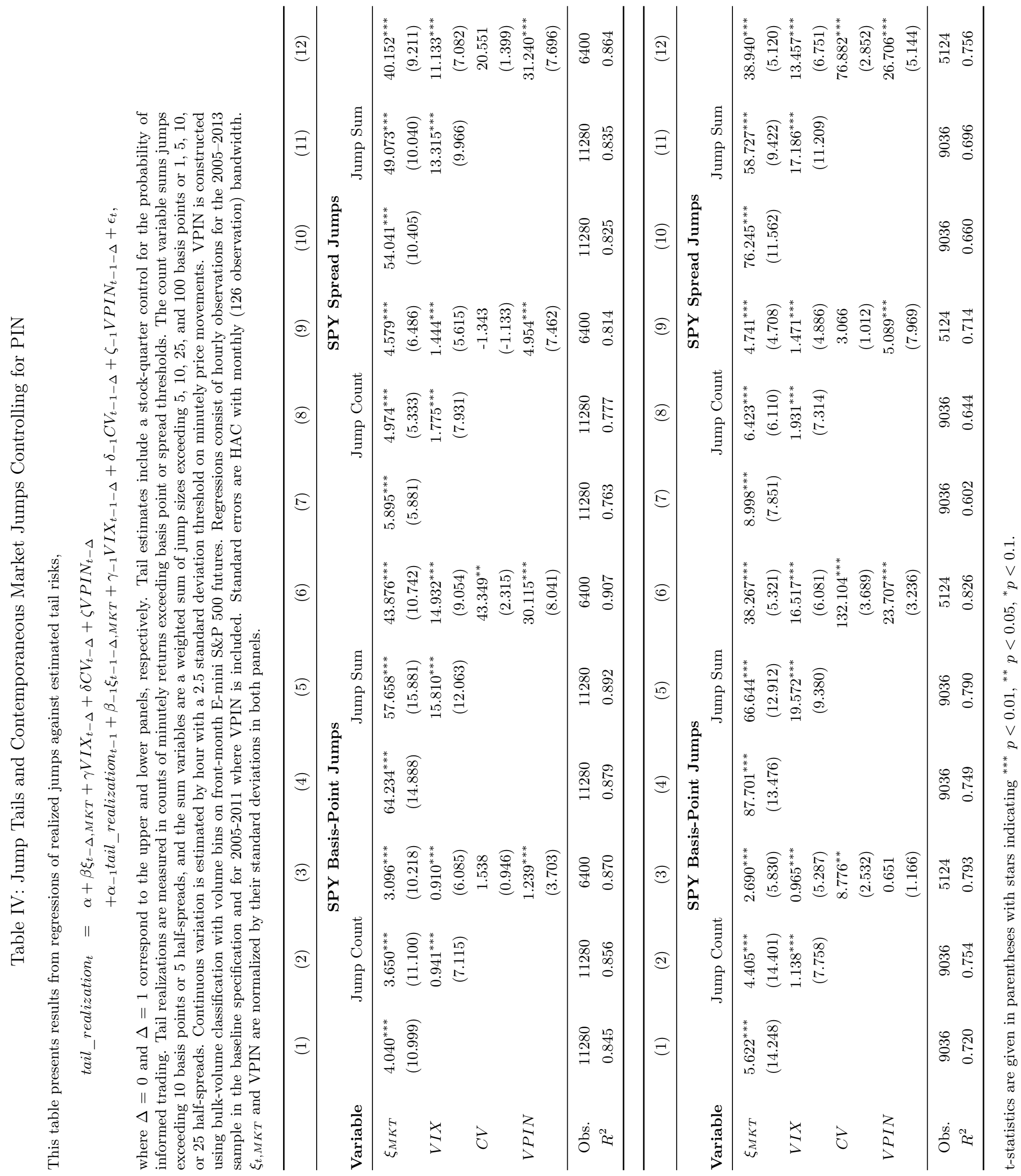




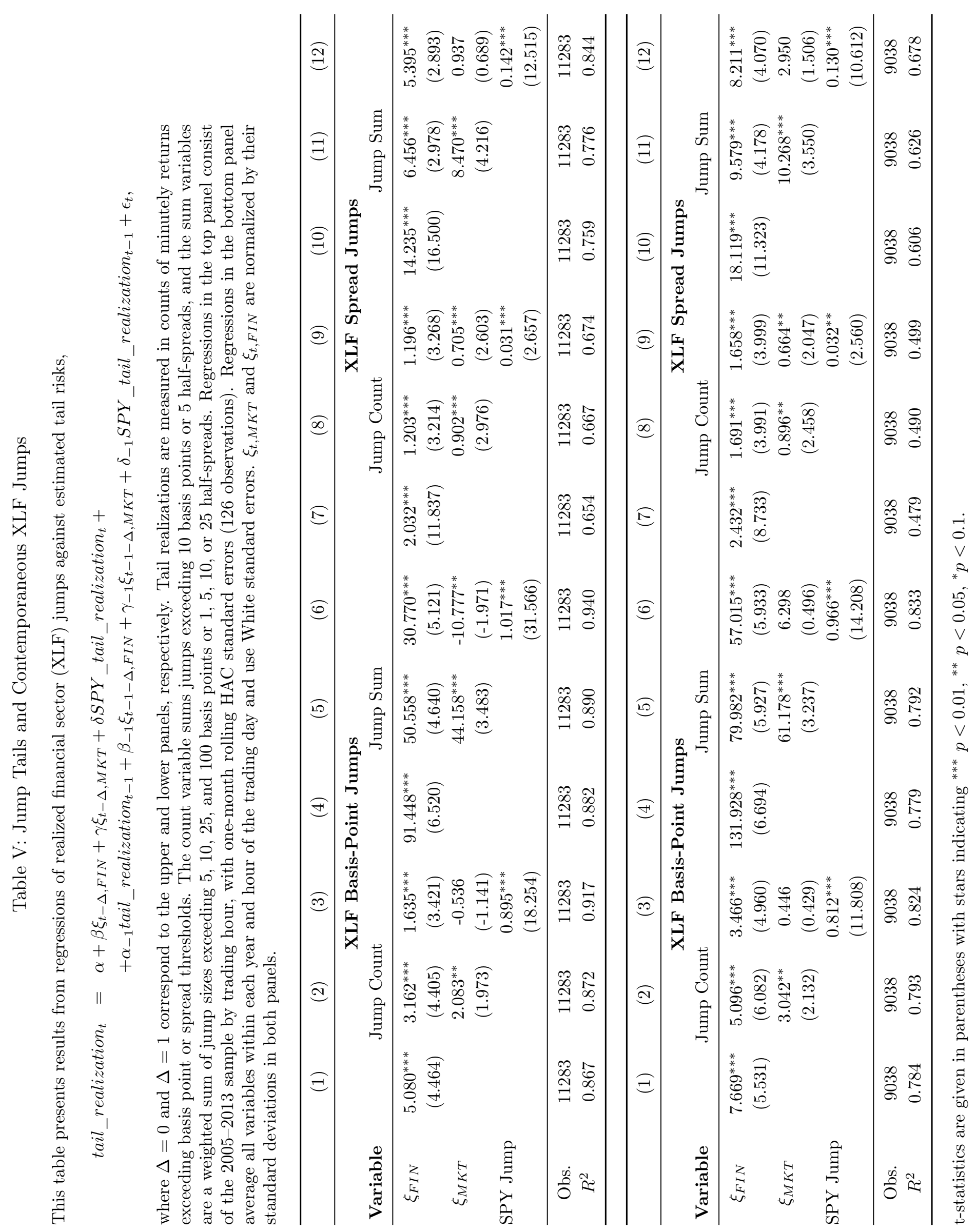




\section{A. Data Filters}

The TAQ database occasionally records erroneous trade price and quantity information. I take three precautions to avoid contamination of the sample and mistaken detection of price jumps in Section V. First, I filter the trade price series following the trade data methodology of BarndorffNielsen, Hansen, Lunde and Shephard (2009). This methodology eliminates most obvious data errors. Second, I adapt the outlier removal procedures of Brownlees and Gallo (2006) (similar to Rule Q4 of Barndorff-Nielsen et al. (2009)) to exclude price observations exceeding the centered median price (excluding the current observation) on $[t-10 \mathrm{~m}, t+10 \mathrm{~m}]$ by 2.5 mean absolute deviations plus a 15-basis point granularity parameter. This filter removes most data errors in the form of rapidly mean-reverting jumps in recorded prices. Finally, I use volume-weighted averages of prices within each minute as raw inputs rather than individual trades or quotes. This procedure smoothes microstructure noise not of interest for my analysis.

The data is lightly filtered to exclude stocks with poorly estimated betas or extreme illiquidity. To be included in the sample, a stock must have:

1. Traded on at least half of the days in which the market has normal trading hours in the observation year;

2. Quoted spreads less than $5 \%$ of the price of the stock;

3. One-sided volume exceeding 200 shares in the trading interval, but less than the 95 th percentile of one-sided volume; and

4. A market beta in $[0.1,2.5]$.

Securities not satisfying all of these conditions are excluded from cross-sectional regressions. Table A.1 breaks down sample attrition by each filter. ${ }^{24}$ The average sample size is approximately 2,800 distinct stocks for each trading hour and 3,200 distinct stocks for each trading day.

The rationale for these filters is as follows. Filters 1 and 2 and the lower bound of filter 3 ensure that the stock is not too thinly traded to be reliable for risk estimation, either for computing betas

\footnotetext{
${ }^{24}$ For conciseness, the table reports sample attrition with $\beta$ s assumed to be known, although I apply the market beta filter separately for each bootstrap sample $r$.
} 
Table A.1: Data Filters

\begin{tabular}{ccc}
\hline & Intraday (hour average) & Daily \\
\hline Beta filter & $96.0 \%$ & $94.2 \%$ \\
Volume filter & $83.0 \%$ & $89.0 \%$ \\
Spread filter & $99.9 \%$ & $99.8 \%$ \\
All filters & $80.8 \%$ & $85.0 \%$ \\
\hline Average sample size & $\mathbf{2 7 7 6 . 8}$ & $\mathbf{3 1 9 1 . 1}$ \\
\hline
\end{tabular}

in the time series or for estimating tail risks in the cross section. The upper bound on volume in filter 3 ensures that results are not driven by "influential" assets with extremely high volume. The distribution of volume is roughly lognormal, but the underlying model cannot accommodate a $\log$ transform of the data to eliminate potential right skew in the dependent variable. Filter 4 accounts for estimation error in the betas; especially large or small betas are likely to be the result of estimation error. In addition, $\beta$ close to zero makes less tenable the assumption of factor jumps being greater than $h / \beta$.

\section{B. Additional Empirical Considerations}

Negative Betas and Return Symmetry

This methodology can accommodate negative asset betas. For illustration, suppose that the additional candidate factor is FIN or "financials," and that financial betas can be of either sign. If jump tails are symmetric, recovering expected jumps entails minimal modification of our previous expressions,

$$
\begin{aligned}
\left(\frac{V h}{d}\right)_{i t} & =\tilde{\xi}+\xi_{M K T} \beta_{i m}+\xi_{F I N} \beta_{i, F I N} \mathbf{1}\left(\beta_{i, F I N}>0\right)-\xi_{F I N} \beta_{i, F I N} \mathbf{1}\left(\beta_{i, F I N}<0\right)+\epsilon_{i} \\
& =\tilde{\xi}+\xi_{M K T} \beta_{i m}+\xi_{F I N}\left|\beta_{i, F I N}\right|+\epsilon_{i} .
\end{aligned}
$$

The first line acknowledges that negative betas only increase half-spreads for buying the asset when the factor's jump return is negative. Collapsing the expression in the first line suggests that taking the absolute value of beta suffices for estimation. 
I implicitly assume symmetry of jumps under $\mathbb{P}$ because the distribution of realized jumps for individual stocks and the SPY and XLF ETFs is very close to symmetric. ${ }^{25}$ This condition can be weakened further: the density need not be symmetric around zero for every jump size. It is sufficient that the tail expectation of jump sizes above $\bar{h}_{k}$ is equal for positive and negative factor moves. Alternatively, Equation (B.1) can be generalized to allow for asymmetric tail expectations:

$$
\begin{aligned}
& \left(\frac{V h}{d}\right)^{R}=\tilde{\xi}^{R}+\xi_{M K T}^{R} \beta_{i, M K T}+\xi_{F I N}^{R} \beta_{i, F I N} \mathbf{1}_{\beta_{i, F I N}>0}-\xi_{F I N}^{L} \beta_{i, F I N} \mathbf{1}_{\beta_{i, F I N}<0}+\epsilon_{i 1}, \\
& \left(\frac{V h}{d}\right)^{L}=\tilde{\xi}^{L}+\xi_{M K T}^{L} \beta_{i, M K T}-\xi_{F I N}^{L} \beta_{i, F I N} \mathbf{1}_{\beta_{i, F I N}<0}+\xi_{F I N}^{R} \beta_{i, F I N} \mathbf{1}_{\beta_{i, F I N}>0}+\epsilon_{i 2}
\end{aligned}
$$

where $R$ and $L$ denote right- and left-jump tails and the corresponding volume and spread proxies. These expressions are readily stacked to obtain a single regression equation in the unknown left and right tail coefficients. ${ }^{26}$

\section{Co-jumps}

I now revisit assumption 2 in the context of Equations (6) and (9). Excluding co-jumps eliminates terms in Equation (6) associated with factors moving jointly. As an example, suppose that the econometrician considers only market and financial return factors and allows for co-jumps between them. Again denoting the financial return factor as FIN, the additional picking-off risk term associated with co-jumps is

$$
+\lambda_{\{M K T, F I N\}} \int_{\beta_{M K T} r_{M K T}+\beta_{F I N} r_{F I N} \geq h}^{\infty}\left(\beta_{M K T} r_{M K T}+\beta_{F I N} r_{F I N}-h\right) d\left(r_{M K T}, r_{F I N}\right) .
$$

This additional term is readily converted into linear terms under the large jumps assumption of Equation (9) if jumps are of the same sign. Under these conditions, the additional term in Equation

\footnotetext{
${ }^{25}$ Jumps detected using Lee and Mykland (2008) and Bollerslev et al. (2013) methodologies share this symmetry property.

${ }^{26}$ I estimate left- and right-jump tails separately in the Internet Appendix and confirm that jump tails are typically (nearly) symmetric, but symmetry breaks down around extreme events such as the 2010 Flash Crash.
} 
(9) is decomposed as

$$
\begin{aligned}
-\lambda_{\{M K T, F I N\}}+ & \lambda_{\{M K T, F I N\}} E\left[r_{M K T} \mid r_{M K T}, r_{F I N}>0\right] \beta_{M K T} \\
& +\lambda_{\{M K T, F I N\}} E\left[r_{F I N} \mid r_{M K T}, r_{F I N}>0\right] \beta_{F I N} .
\end{aligned}
$$

If jump signs differ, additional terms arise resulting from different combinations of the signs of the co-jump returns.

In my multivariate analysis of market and financial jumps, I omit these additional terms because (1) the correlation between SPY and XLF returns is positive and extremely strong, on the order of $89 \%$ in my sample, and (2) the absorption of the co-jump terms $\lambda_{\{M K T, F I N\}} \times$ $E\left[r_{M K T} \mid r_{M K T}, r_{F I N}>0\right]$ and $\lambda_{\{M K T, F I N\}} \times E\left[r_{F I N} \mid r_{M K T}, r_{F I N}>0\right]$ has a clear associated economic intuition. The total coefficient on $\beta_{M K T}$ is the tail risk of the market with or without financial co-jumps, which arguably is of greater interest than either component of market tail risk independently.

\section{Liquidity Maker and Taker Fees}

I add liquidity rebates to effective half-spreads to obtain the gross of fees benefit of liquidity provision that accrues to market makers. I assume that rebates are roughly constant across stocks (i.e., that Tape A vs. B vs. C differences are small) and equal to 22 cents per 100 shares. This average rebate size is found in the present-day NYSE price list for the most active liquidity providers (Tier 1; https://www.nyse.com/markets/nyse/trading-info), in Table 1 of the maker-taker analysis of Foucault, Kadan and Kandel (2013) (who in turn reference a 2009 publication), as well as in a recent comprehensive study of maker-taker fees as the average value for active liquidity providers from January 2008 through December 2010 (Cardella, Hao and Kalcheva (2015)). I omit consider-

ation of taker fees and small-market-share "inverted" fee exchanges. Liquidity taker fees drop out in the linear model of Equation (9) because they are subsumed into the lower bound of integration for each factor.

Because rebates are typically small relative to the spread, reasonable alternatives for the level 
of the rebate have minimal effect on results. For example, reducing the rebate from $\$ 0.22$ per hundred shares to $\$ 0.00$ maintains the same shape in the time series of jumps while shifting the recovered idiosyncratic tail risk down slightly. In addition, rebate measurement errors contaminate the dependent variable and are likely to be uncorrelated with asset betas, so rebate mismeasurement should have little effect on factor tail risk estimates. 